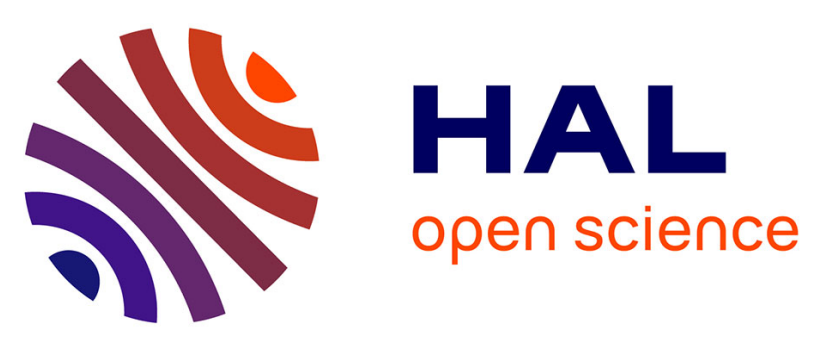

\title{
A phenomenological study of the influence of the hardening type on the indentation F-h cyclic curve
}

M. Idriss, Olivier Bartier, Gerard Mauvoisin, Xavier Hernot

\section{To cite this version:}

M. Idriss, Olivier Bartier, Gerard Mauvoisin, Xavier Hernot. A phenomenological study of the influence of the hardening type on the indentation F-h cyclic curve. International Journal of Mechanical Sciences, 2021, 197, pp.106336. 10.1016/j.ijmecsci.2021.106336 . hal-03159346

\section{HAL Id: hal-03159346 \\ https://hal.science/hal-03159346}

Submitted on 8 Mar 2021

HAL is a multi-disciplinary open access archive for the deposit and dissemination of scientific research documents, whether they are published or not. The documents may come from teaching and research institutions in France or abroad, or from public or private research centers.
L'archive ouverte pluridisciplinaire HAL, est destinée au dépôt et à la diffusion de documents scientifiques de niveau recherche, publiés ou non, émanant des établissements d'enseignement et de recherche français ou étrangers, des laboratoires publics ou privés. 
A phenomenological study of the influence of the hardening type on the indentation F-h cyclic curve Mohamad IDRISS $^{1 *}$, Olivier BARTIER ${ }^{2}$, Gérard MAUVOISIN ${ }^{2}$, and Xavier HERNOT ${ }^{2}$

${ }^{1}$ CTA-ATS, National Research Council (NRC-CNRC), QC G7H 8C3, Saguenay, Canada

${ }^{2}$ LGCGM, Université Rennes 1, 3 Rue du Clos Courtel, 35700, Rennes, France

\section{Abstract}

This paperis a phenomenological study representing the influence of the hardening type on the instrumented indentation $\mathrm{F}$ - $\mathrm{h}$ curve. Spherical instrumented indentation and inverse analysis techniques (IAT) are used and two metallic materials (DP600 and AA2017) are investigated. Pure isotropic (Voce) and combined (Chaboche 1986) hardening laws are adopted for describing the plastic behavior of the studied materials. The influence of the hardening type on the indentation loading curve is studied first. Kinematichardening results in softening the indentation loading curve. This is due to some regions in the indented zone that undergo different loading paths during loading. Hardening types (kinematic \& isotropic) should be considered to accurately characterize the mechanical behaviour of different metallic materials using indentation curves. The influence of the hardening type on the indentation unloadingreloading curve (hysteresis loop) is then studied. Kinematic hardening has an important influence on the hysteresis loop. This influence has been investigated closely and a methodology is proposed for estimating the contribution of each hardening type in the overall hardening behavio $r$. This methodology is based on geometrical parameters directly influenced by the hardening type and presents great potential if considered in future works aiming to identify parameters of relatively complex hardening laws using the instrumented indentation technique (IIT).

Keywords: Instrumented Indentation, Inverse analysis, Isotropic and Kinematic hardening, Finite Element Analysis, Hysteresis loop. 
Highlight

- Indented regions undergo multi-paths loading during indenter penetration

- Kinematic hardening softens the loading indentation curve: Bauschinger effect

- Hardening type influences geometrical parameters of the hysteresis loop

- A dimensionless geometric ratio is proposed for successfully determining each hardening type

- The proposed approach will help to identify more complex hardening laws using indentation 


\section{Graphical-Abstract}

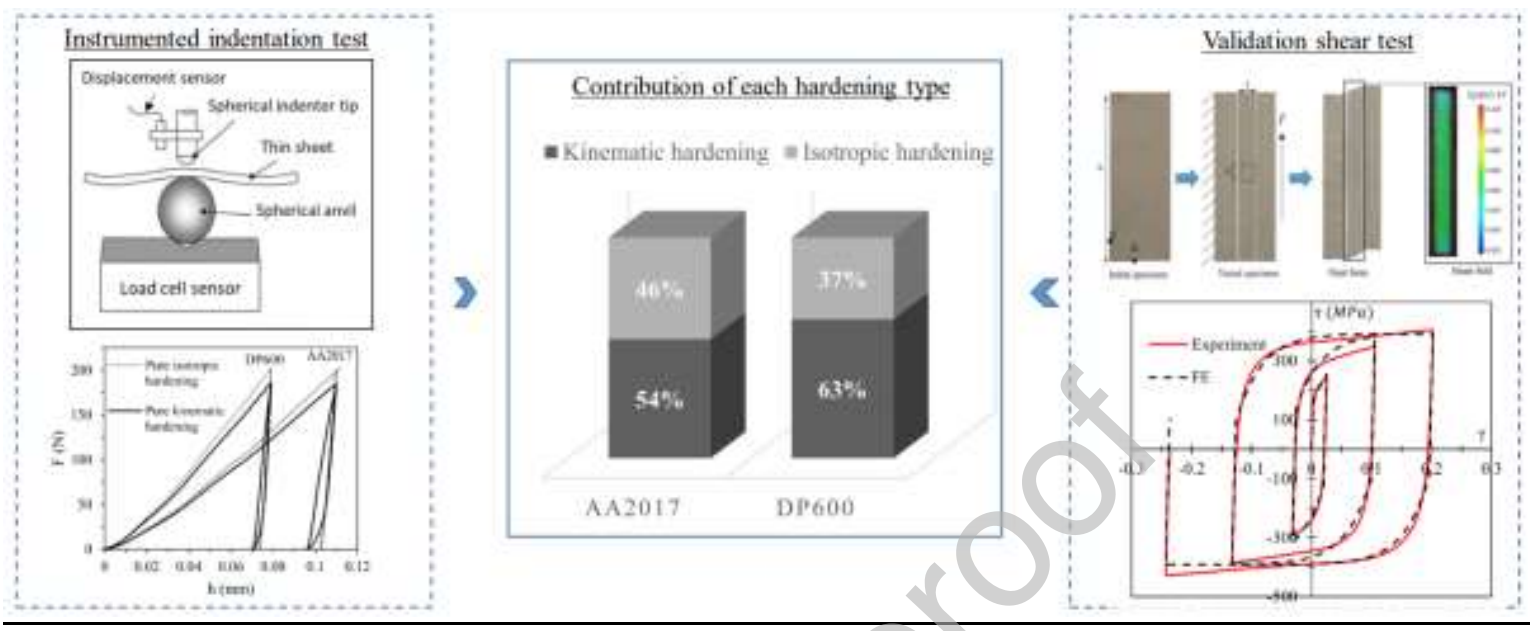

\section{Introduction}

In 1822, Mohs published the first work related to hardness testing [1]. Hertz and Brinell made important advances in this same field at the beginning of the $20^{\text {th }}$ century [2] [3]. In the 1950 s, D. Tabor put in place a foundational cornerstone book concerning the hardness of metals [4] [5]. The next advancement leap was obtained when the hardness test was instrumented and researchers began measuring in-situ the variation of indentation loading as a function of the indentation depth [6] [7]. Afterward, instrumented indentation knew enormous improvements with different theoretical and analytical contributions [8] [9] [10], FE modeling [11] [12] [13] [14], and experimental enhancements beginning from indenting at different scales (nano [15] [16] [17], micro [18] [19] [20], and macrohardness [21] [22]), using different types of indenters (conical [23] [24] , Berkovich [17] [24] or spherical 
[25] [26] [27]) and not ending with considering the exact form of the indenter tip in FE computations [28] [29] [30].

In the case of a spherical indenter, the instrumented indentation technique (IIT) consists of pressing a ball in the studied material and recording the evolution of the pressing force $F(N)$ as a function of the penetration depth $h(\mathrm{~mm})$. Based on the obtained indentation $F$ - $h$ curve, different approaches were developed for determining the stress-strain relationship of the studied material in the elastic and plastic domains [12] [18] [19] [20] [26] [31] [32] [33].

Despite the adopted approach, the vast majority of the studies considers the tested material to follow Hollomon power law in its plastic domain where only 2 plastic parameters are to be determined (Yield stress $\left(\sigma_{Y}\right)$ and hardening coefficient $(n)$ ) [11] [12] [13] [20] [34] [35] [36] [37] [38]. In a recently developed approach, C. Moussa et al. [19] [32] put in place a database of hundreds of numerical indentation curves obtained from FEM by varying both parameters of Hollomon law. The latter parameters of a tested material are determined by minimizing a cost function between the corresponding experimental indentation curve and numerical indentation curves from the database [31]. Other studies coupled IIT to the inverse analysis technique (IAT) to determine both plastic parameters of the Hollomon law [20] [39] [40] [41] [42]. This last approach is promising due to its simplicity where no analytical model is to be used. However, special attention is to be given to the non unicity problem of the obtained solution [43] [44] [45].

Using IIT coupled to IAT, other studies tried identifying more than two elastic and plastic mechanical parameters. N. Chollacoop etal. [43] used instrumented sharp indentation with dual sharp indenters coupled to IAT to determine 3 elastic-plastic parameters $\left(E, \sigma_{y}\right.$ and $\left.n\right)$. The use of two indenters led to reducing the non-uniqueness problem and improving the accuracy. J.J. Kang et al. [46] used conical indentation coupled to IAT to determine 2 elastic and 2 plastic parameters of a hardening 
law $\left(E, v, \sigma_{y}\right.$ and $\left.n\right)$. Results were accurate when determining $\sigma_{y}$ but less accurate when determining $E$ and $n$. S. Kucharski et al. [25] tried to identify the 3 plastic parameters of Ludwig power law. They propose to measure in addition to the indentation load and depth, the contact radius. However, the latter dimension cannot be easily determined experimentally. In addition, their method is very sensitive to the accuracy of the contact radius measurement. Based on studies showing that spherical indentation can identify the stress-strain relationship of non-power-law materials [4] [11], M. Idriss et al. [18] proposed a new methodology to determine 3 plastic parameters of Voce exponential law [47]. The nonunicity problem was avoided by extensive repetitions of the same computation varying at each time the allowable range of the identified parameters. Therefore, the obtained solution with the minimum cost function is adopted. The proposed methodology led to reliable results but is energy and timeconsuming.

In all these studies, the hardening type of tested material is considered purely isotropic. However, many metallic materials show a significant contribution of kinematic hardening to the total hardening behavior. The influence of the hardening type on the indentation curve was previously studied by $\mathrm{N}$. Huber et Ch. Tsakmakis [48] [49] [50] [51]. The latter authors observed a softening of the indentation loading curve due to kinematichardening [52]. These results agree with those obtained numerically by J.M. Collin et al. [53] but contradict what is obtained by Pane and Blank [54] and Shedbale et al. [55]. By studying the plastic strain field under spherical indentation Pane et Blank [54] show that materials dominated by kinematic hardening exhibit stronger plastic strain development. For the authors, the different trend between kinematic and isotropic hardenings is attributed to the fact that yield stress during cyclic loading changes significantly with kinematic hardening but not with isotropic hardening. They also show that in materials dominated by kinematic hardening, yielding can also occur during unloading. Han et al. [56] demonstrated that isotropic hardening cannot be applied alone to simulate 
the indentation ratcheting response of various pseudo materials. Accordingly, they concluded that a constitutive model including kinematic hardening allows correct simulations of cyclic indentation.

The influence of kinematic hardening on indentation response led various researchers to try identifying parameters of mixed isotropic-kinematic hardening laws from cyclic indentation tests (loading-unloading-reloading). N. Huber et Ch. Tsakmakis combined FEM to neural networks technique to identify, from an indentation cyclic curve, 5 parameters considering both hardening types [48] [49]. The obtained stress-strain curves are satisfying when compared to simple tensile tests. However, no validation was made with non-monotonic tests where kinematic hardening is 'expressed' by the presence of the Bauschinger effect. J.M. Collin et al. used indentation cyclic curves to determine 5 plastic parameters of the Chaboche hardening law [53] [57]. The adopted law considers both hardening types but the non-unicity problem was always encountered. For Sajjad et al. [58], yield strength cannot be determined based only on force-displacement curves obtained with sharp indenters. Assuming that yield strength is known, they determine the remaining hardening parameters of Chaboche's law from the indentation hysteresis loop. Based on the identified parameters, the Chaboche model was employed to predict successfully the cyclic stress-strain responses of tempered martensitic steel, SAE 4150 with different heat treatments, and pure copper. Furthermore, they observe that the difference between the maximum and minimum force of the hysteresis loop obtained from cyclic indentation has a direct correlation with the stress amplitude of the hysteresis loop obtained from strain-controlled uniaxial fatigue tests. For the authors, the prediction of a complete cyclic stress-strain curve by using data from cyclic indentation has great potential to reduce time- and cost-intensive fatigue experiments and can thus open a new and economic way to predict the fatigue life of materials with a quasi-nondestructive test method. 
In this paper, a phenomenological study investigates the influence of kinematic hardening on the indentation cyclic curve in the case of 2 metallic materials (DP600 and AA2017). The observations of N. Huber et Ch. Tsakmakis [52] concerning the influence of kinematic hardening on the indentation loading curve are validated using a numerical approach where plastic strains, for a given point from the indented zone, are investigated at different indentation depths. Afterward, the influence of kinematic hardening on the hysteresis loop is investigated. A novel approach is proposed permitting to determine, using IIT, the contribution of each hardening type on the overall hardening law of the studied materials. The obtained results are then compared to results obtained from cyclic shear tests where both hardening types govern the stress-strain behavior.

\section{Theoretical background: constitutive model}

To investigate the influence of kinematic hardening on the cyclic indentation and shear results, finite element simulations are carried out using Abaqus. Both elastic and plastic deformations are considered and elastic-plastic constitutive laws are written within a large transformation framework. Elasticity and plasticity are assumed isotropic. The stress-elastic strain relationship depends on Lamé's coefficients $\lambda$ and $\mu$ and during plasticity, the strain hardening, characterized by the expansion and shift of the yield surface with accumulating plastic strain is described by the Chaboche law [57] [59].

The constitutive model of elastic-plastic materials follows the J2-associated flow theory with rateindependent deformation. For metals with both isotropic and kinematic hardening types, yield function $f$ with Von-Mises criterion can be written as:

$f(\overline{\bar{\sigma}}-\overline{\bar{X}}-R)=J_{2}(\overline{\bar{\sigma}}-\overline{\bar{X}})-R-\sigma_{Y}$

Where, $\overline{\bar{\sigma}}$ is the stress tensor, $\overline{\bar{X}}$ is the kinematic hardening tensor, $\mathrm{R}$ is the scalar valued variable describing effects of the isotropichardening, $\sigma_{Y}$ is the yield stress and $J_{2}(\overline{\bar{\sigma}}-\overline{\bar{X}})$ is the equivalent von Mises stress with respect to the backstress tensor $\overline{\bar{X}}$, defined as: 
$J_{2}(\overline{\bar{\sigma}}-\overline{\bar{X}})=\sqrt{\frac{3}{2}\left(\overline{\bar{S}}-\overline{\overline{X_{d}}}\right):\left(\overline{\bar{S}}-\overline{\overline{X_{d}}}\right)}$

Where $\overline{\bar{S}}$ is the deviatoricstress tensor, and $\overline{\overline{X_{d}}}$ is the deviatoric part of the backstress tensor. The evolution of plasticity is tracked by the equivalent plastic strain $\varepsilon_{p}^{e q}$, defined as:

$\varepsilon_{p}^{e q}=\int_{\Omega} \varepsilon_{p}^{\dot{e q}}=\int_{\Omega} \sqrt{\frac{2}{3} \overline{\overline{\varepsilon_{p}}}: \frac{\dot{\overline{\varepsilon_{p}}}}{}}=\int_{\Omega} \dot{\lambda}$

Where $\Omega$ is the strain path used to track the accumulation of plasticity, $\dot{\overline{\varepsilon_{p}}}$ is the plastic part of the strain rate tensor and $\varepsilon_{p}^{\dot{e} q}$ is the equivalent plastic strain rate which corresponds to the positive plastic flow multiplier, $\dot{\lambda}$.

This holds because of the assumption of an associated flow rule (normality rule):

$\dot{\overline{\overline{\varepsilon_{p}}}}=\dot{\lambda} \frac{\partial f}{\partial \overline{\bar{\sigma}}}=\dot{\lambda} \frac{3}{2} \frac{\left(\overline{\bar{S}}-\overline{\overline{X_{d}}}\right)}{(\overline{\bar{\sigma}}-\overline{\bar{X}})}$

A common representation of the combined hardening behavior was proposed by J.L. Chaboche [60], the kinematichardening evolution rule is based on the Armstrong and Frederick formulation [59] and the isotropic hardening evolution rule was proposed by Voce [47]:

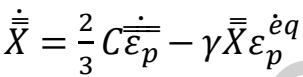

$\dot{R}=b(Q-R) \varepsilon_{p}^{\dot{e} q}$

Where $C$ and $\gamma$ are kinematic hardening parameters and $Q$ and $b$ are isotropic hardening parameters. For uniaxial stress state, the monotonicstrain-stress relation is described by the Chaboche law as following:

$\sigma=\sigma_{Y}+X+R$

Where the contribution of the kinematic hardening is: 
$X=\frac{C}{\gamma}\left(1-\exp \left(-\gamma \varepsilon_{p}\right)\right)$

And the contribution of the isotropic hardening is:

$R=Q\left(1-\exp \left(-b \varepsilon_{p}\right)\right)$

\section{Materials and mechanical tests}

2 metallic materials, presenting relatively important kinematic hardening [61] [62] [63], are studied:

- DP600: Dual-phase (Martensite + Ferrite) steel with relatively high yield strength.

- AA2017-T4: Aluminum alloyed mainly to Cupper with relatively low Young's modulus. The T4 condition means that the material was solution treated, quenched, and naturally aged.

Both materials are cold-rolled sheets with $2 \mathrm{~mm}$ and $1 \mathrm{~mm}$ thicknesses for DP600 and AA2017, respectively. Corresponding chemical compositions and microstructures were presented in a previous study [18].

\subsection{Tensile and shear tests}

Tensile tests are performed following the EN ISO 6892-1 standard [64]. All the needed information concerning the sample dimensions and test conditions were extensively presented in [18]. Anisotropic behavior for both metals in the sheet metal plane is not considered for the rest of the study. Both materials exhibit relatively close yield strengths but DP600 hardens much more than AA2017 (fig. 1).

Shear tests are performed in LIMATB Laboratory at UBS University in France. The used apparatus and the corresponding methodology were extensively explained in [65]. Two types of shear tests are conducted: 
- Monotonic shear tests where relatively high strain levels are obtained (fig. 1).

- Cyclic shear tests for identifying hardening types (isotropic and kinematic).

For shear testing, $50 \times 18 \mathrm{~mm}^{2}$ and $30 \times 18 \mathrm{~mm}^{2}$ rectangular specimens are cut from AA2017 and DP600 sheets, respectively. A working width (I) of $4 \mathrm{~mm}$ is adopted to avoid buckling (fig. 2).

Force values are measured using a load cell with a maximum capacity of $100 \mathrm{kN}$. Image correlation Aramis system, developed by GOM, is used to measure displacements. The $\varepsilon_{X Y}$ component of the strain tensor (with $\vec{X}$ the transverse direction in the sheet plane and $\vec{Y}$ the shear direction) is measured on a rectangle of $25 \mathrm{~mm}(\mathrm{~h})$ high for the AA2017 and $3 \mathrm{~mm}(\mathrm{~h})$ high for the DP600 in the center of the tested samples (fig. 2). This difference is due to the fact that for DP600, the homogeneous deformed zone is smaller than the one obtained in the case of AA2017. Shear strains are determined from the average values of the measured $\varepsilon_{X Y}$ strains using (eq. 10). Shear stress is calculated using (eq. 11).

$\gamma=2 * \varepsilon_{X Y}$

$\sigma_{X Y}=\tau=F /(L * e)$

Where $F(N)$ is the measured force, $L(\mathrm{~mm})$ the total length, and e $(\mathrm{mm})$ the thickness of the specimen.

For obtaining comparable results to tensile curves, equivalent stress, and strain $\sigma_{e q}-\varepsilon_{e q}$ are calculated from $\sigma_{X Y}-\varepsilon_{X Y}$ based on Von-Mises transformations (eq. $12 \&$ eq. 13). Based on fig. 1, tensile and shear curves correlate perfectly for both materials. This proves that the use of Von-Mises criterion for the calculation of equivalent stress and strain is relevant for both metal sheets.

$\sigma_{e q}=\sqrt{3} * \sigma_{X Y}$

$\varepsilon_{e q}=\frac{2}{\sqrt{3}} * \varepsilon_{X Y}$ 


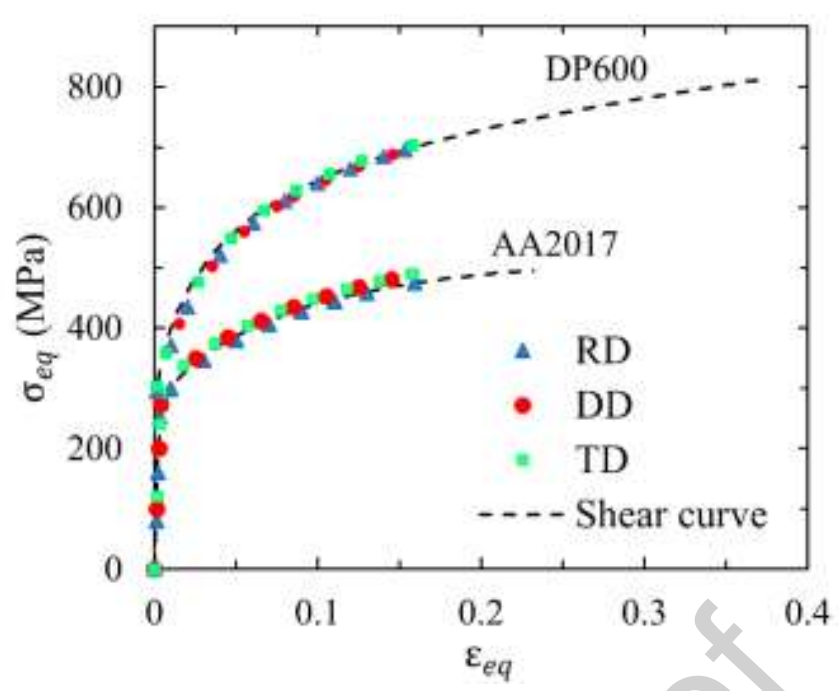

Fig. 1. (Colour online) Hardening curves of the metal sheets obtained from tensile and monotonic shear tests for both tested materials:DP600 and AA2017-T4. For each material, the blue triangles curve corresponds to the mean curve of 3 tensile curves obtained on 3 specimens cut in the rolling direction of the corresponding tested material. Red dots and green squares curves are obtained similarly to blue triangles curves but corresponding specimens are cut in diagonal and transversal directions, respectively. Black dashed curves are the mean shear curves obtained from 2 shear specimens: equivalent stresses and strains are calculated using the Von-Mises criterion.

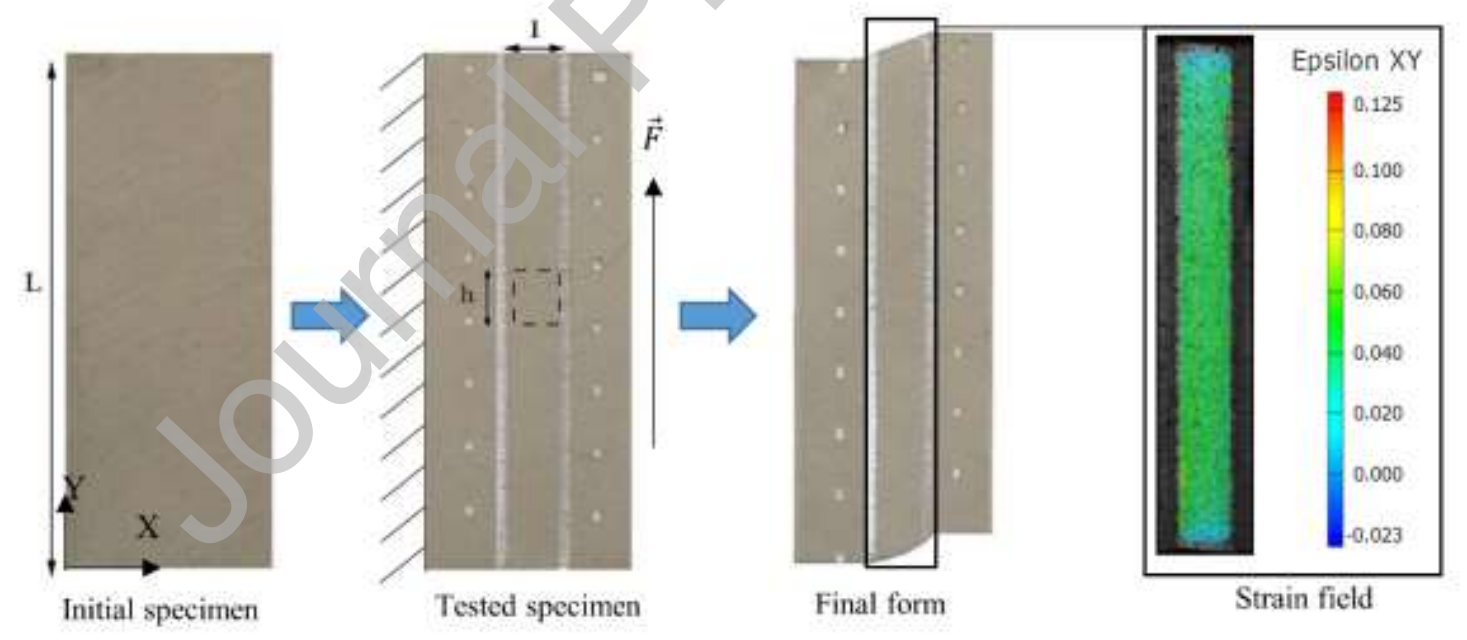

Fig. 2. Shear specimen [66] and the corresponding strain field after testing. The first figure shows the initial form and dimensions of the tested specimen. The second figure is the form of the specimen during shear testing: the specimen is fixed on one end and shear force is applied on the other end. The final form corresponds to the specimen form after shear testing. The strain field corresponds to what is obtained using the image correlation Aramis system: the strain field is mainly homogeneous especially in the center of the sheared zone. 
The corresponding numerical model is one solid C3D8R element with one integration node. The solicitation is applied by blocking one face of the element and by imposing the displacement to the opposing one.

Finally, for cyclic shear tests, IAT is used to determine Chaboche parameters. The adopted cost function $E_{1}$ is given in (eq. 14).

$E=\frac{\sum_{i=1}^{n-1}\left|\left(\frac{\left(\tau_{\text {xynum }}^{i+1}-\tau_{\text {xyexp }}^{i+1}\right)^{2}+\left(\tau_{\text {xynum }}^{i}-\tau_{\text {xyexp }}^{i}\right)^{2}}{2}\right) *\left(\frac{\left|\gamma_{\text {xyexp }}^{i+1}-\gamma_{x y \exp }^{i}\right|+\left|\gamma_{\text {xynum }}^{i+1}-\gamma_{\text {xynum }}^{i}\right|}{2}\right)\right|}{\sum_{i=1}^{n-1}\left|\frac{\gamma_{\text {xyexp }}-\gamma_{\text {xyexp }}^{i}|+| \gamma_{\text {xynum }}^{i+1} \gamma_{\text {xynum }}^{i} \mid}{2}\right|}$ (eq. 14)

Where $\tau_{\text {xymum }}(\mathrm{MPa})$ is the numerical shear stress, $\tau_{\text {xyexp }}(\mathrm{MPa})$ is the experimental shear stress, $\gamma_{x y n u m}$ is the numerical shear strain and $\gamma_{x y \exp }$ is the experimental shear strain.

\subsection{IIT and Inverse analysis technique (IAT)}

The home-made instrumented indentation bench was extensively presented in previous papers and patents of the authors [18] [67]. A home-made software allows obtaining simultaneously time (s), displacement $(\mathrm{mm})$, and applied load $(\mathrm{N})$. The adopted indentation procedure follows the general recommendation of standard EN ISO 14577-1 [68]. A rounded tip tungsten carbide indenter with a 0.25 $\mathrm{mm}$ nominal radius is used for obtaining the indentation curves. A spherical tungsten carbide support of $R=140 \mathrm{~mm}$ is used for ensuring contact with the lower surface of the tested sheet [67]. $40 * 40 \mathrm{~mm}^{2}$ samples are cut and polished (1200 grit) on both surfaces before conducting the indentation tests. 
Indentation tests are repeated at least three times on each sample to ensure reproducibility (fig. 3). Afterward, the mean curve is deduced and adopted for the rest of the study.

Previous studies observed a grain size effect on the indentation curve [69] [70]. VM Matyunin et al. [70] conclude that in the case of hardness determination of materials with a mixed microstructure, e.g. perlite and ferrite, it is necessary to ensure that the minimum number of grains of the mixed microstructure in the indentation zone is at least $3-5$. In this work and in order to avoid the grain size effect, a relatively high maximum load level is considered ( $200 \mathrm{~N}$ ). fig. 4 (a-b) compares the grain size to the size of an indent corresponding to a $200 \mathrm{~N}$ loading (represented as black dashed circles). Corresponding procedures for obtaining the microstructure of each tested material were extensively detailed in [18]. Fig. 4 (a-b) shows that grain size, for both teste d metals, is very small when compared to the indent size. Thus, grain size has minimal effect on the indentation curve. With the load level adopted, the indentation test reveals the main characteristics of the material deformation mechanism at macro and meso levels, as in the case of tensile or shear tests [69].

In particular cases, strain rates can influence indentation results [71] [72]. In this work, a constant crosshead velocity of $1 \mu \mathrm{m} / \mathrm{s}$ is adopted for all the indentation tests. For this crosshead velocity, the corresponding indentation strain rate drops to less than $0.002 \mathrm{~s}^{-1}$ when penetration depths exceed approximately 15 microns [72]. Thus, in this study, indentation tests are conducted in a quasistatic regime where strain rates don't influence the obtained indentation curves [72].

The corresponding FE indentation models were detailed in [18]. Coulomb friction coefficients $\mu$ of 0.1 and 0.15 are considered for the tungsten carbide-steel and tungsten carbide-aluminum contacts, respectively. The experimental indentation bench and the corresponding FE model will be recalled later in figs. 12-a and 12-c. 
IAT was used to identify Voce plastic parameters by minimizing cost function $E_{2}$ (eq. 15) between numerical indentation loading curves and corresponding experimental indentation loading curves.

$E_{2}\left(h_{\max } / R\right)=\frac{1}{h_{\max }} \int_{0}^{h_{\max }}\left(F_{\text {ref }}-F_{\text {num }}\right)^{2} \cdot d h$

The identified Voce parameters in [18] using IIT coupled to IAT are recalled in table 1. In this study, IIT is also used to obtain numerical and experimental indentation cyclic curves which will be used for evaluating the part of each hardening type in the overall hardening behaviour of the tested material.

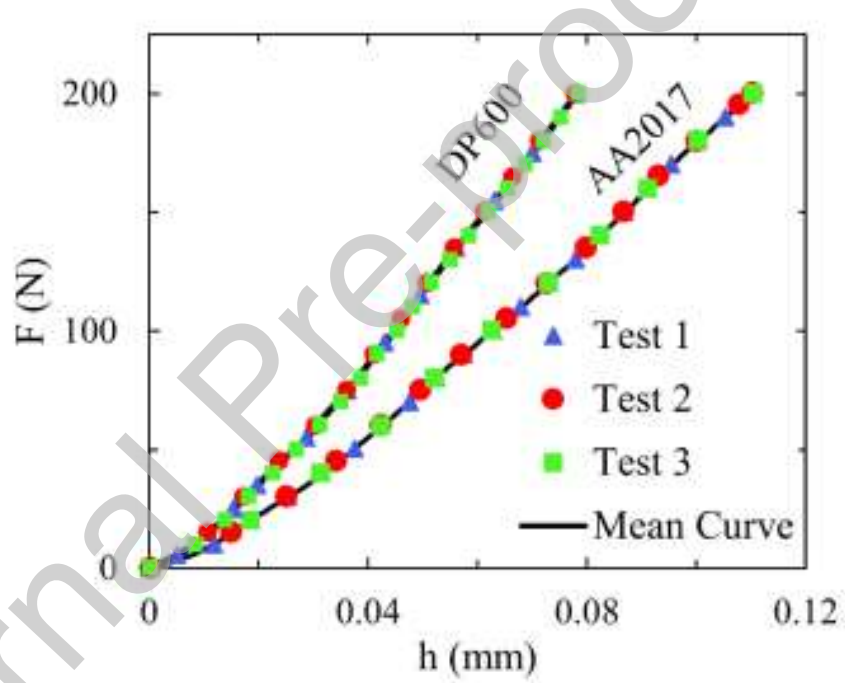

Fig. 3. Experimental F-h loading indentation curves and corresponding mean curves obtained for both tested materials: the maximum load is $200 \mathrm{~N}$. 

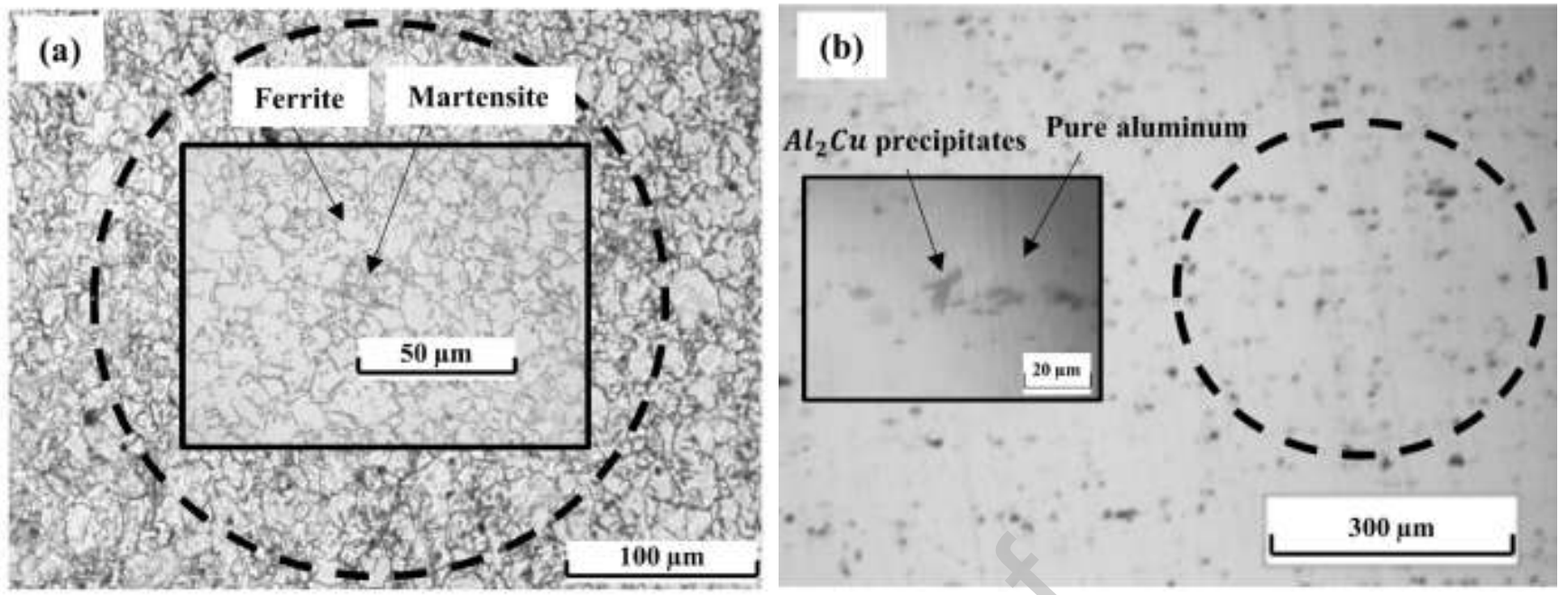

Fig. 4. Microstructure of the studied metals: (a) DP600, (b) AA2017: grain size compared to indent size (black dashed circle)

Table 1 Identified Voce law parameters for both tested materials using IIT and IAT [18]

\begin{tabular}{llll} 
& $\boldsymbol{\sigma}_{y-V}$ & $\boldsymbol{Q}_{\boldsymbol{V}}$ & $\boldsymbol{b}_{\boldsymbol{V}}$ \\
\hline $\mathrm{DP600}$ & 419 & 1175 & 1.73 \\
\hline AA2017 & 304 & 745 & 1.71 \\
\hline
\end{tabular}

\section{Results and discussion}

\subsection{Preliminary computations and hypothesis}

Chaboche hardening law is adopted for evaluating the influence of each hardening type on the indentation curve. For a consistent evaluation, Chaboche parameters are varied in a way that the overall hardening law remains unchanged in the case of monotonic uniaxial loading (e.g. tensile or monotonic shear tests). Based on Von-Mises transformations, this leads to (eq. 16) where, for any given equivalent plastic strain in the loading direction, the corresponding stress from Chaboche equation is equivalent to the stress calculated using Voce parameters (table 2). 


$$
\sigma=\sigma_{Y}+Q *\left(1-\exp \left(-b * \varepsilon_{p}\right)\right)+\frac{c}{\gamma} *\left(1-\exp \left(-\gamma * \varepsilon_{p}\right)\right)=\sigma_{Y-V}+Q_{V} *\left(1-\exp \left(-b_{V} * \varepsilon_{p}\right)\right)
$$

Where $\sigma_{Y-V}, Q_{V}$ and $b_{V}$ are the Voce parameters identified in [18]. $\sigma_{Y}, Q, C, b$ and $\gamma$ are Chaboche parameters describing the mixed hardening behavior law.

Identifying the same material leads to $\sigma_{Y-V}=\sigma_{Y}$. In addition, it is considered that the curvature of the hardening law is equally influenced by both hardening types. Therefore, $b=\gamma=b_{V}$. Results remain relevant especially since, in the case of a uniaxial monotonic load, one exponential component is generally sufficient to describe the curvature of the hardening law. $b \neq \gamma$ means that the evolution of kinematic hardening is different from the evolution of isotropic hardening as a function of the equivalent plastic deformation. Due to the complexity of the stress field under the indenter during testing, the equivalent plastic deformation in the case of indentation of a material with a hardening law more complex than Hollomon's law has not yet been proposed in the literature. The assumption that $b=\gamma$ is not physically supported but it is the only way to estimate the influence of the hardening type on the indentation curve without introducing false assumptions about the value of the representative indentation deformation.

Therefore, eq. 16 is simplified to eq. 17 where the part of each hardening type in the overall hardening behavior is varied without modifying the overall hardening law in the case of a monotonic uniaxial loading. Table 2 summarizes, for both materials, 6 different cases where hardening parameters related to the hardening type are varied without varying the overall hardening law.

$Q+\frac{C}{\gamma}=Q_{V}$ 
Fig. 5 represents, for each material, the 2 indentation cyclic curves corresponding to cases 1 and 6 (pure isotropic hardening and pure kinematic hardening, respectively). Hardening type influences the indentation loading curve as well as the hysteresis loop (fig. 5).

Table 2 Chaboche law parameters (a) DP600 (b) AA2017

\begin{tabular}{cccccc}
\hline (a) DP600 & \multicolumn{4}{c}{ Chaboche parameters } \\
\hline case & $\begin{array}{c}\text { \% of kinematic } \\
\text { hardening }\end{array}$ & $\boldsymbol{C}$ (MPa) & $\mathbf{Q}$ (MPa) & $\boldsymbol{\gamma}=\boldsymbol{b}_{\boldsymbol{V}}$ & $\begin{array}{c}\boldsymbol{\sigma}_{\boldsymbol{Y}} \\
\text { (MPa) }\end{array}$ \\
\hline $\mathbf{1}$ & 0 (pure isotropic) & 0 & 1175 & 1.73 & 419 \\
\hline $\mathbf{2}$ & 25 & 507 & 881 & 1.73 & 419 \\
\hline $\mathbf{3}$ & 50 & 1013 & 588 & 1.73 & 419 \\
\hline $\mathbf{4}$ & 60 & 1216 & 470 & 1.73 & 419 \\
\hline $\mathbf{5}$ & 75 & 1520 & 294 & 1.73 & 419 \\
\hline $\mathbf{6}$ & 100 (pure kinematic) & 2027 & 0 & 1.73 & 419 \\
\hline
\end{tabular}

\begin{tabular}{cccccc}
\hline (b) AA2017 & \multicolumn{5}{c}{ Chaboche parameters } \\
\hline case & $\begin{array}{c}\text { \% of kinematic } \\
\text { hardening }\end{array}$ & $\boldsymbol{C}$ (MPa) & $\mathbf{Q}$ (MPa) & $\boldsymbol{\gamma}=\boldsymbol{b}_{\boldsymbol{V}}$ & $\begin{array}{c}\boldsymbol{\sigma}_{\boldsymbol{Y}} \\
\text { (MPa) }\end{array}$ \\
\hline $\mathbf{1}$ & 0 (pure isotropic) & 0 & 745 & 1.71 & 304 \\
\hline $\mathbf{2}$ & 25 & 318 & 558 & 1.71 & 304 \\
\hline $\mathbf{3}$ & 50 & 636 & 372 & 1.71 & 304 \\
\hline $\mathbf{4}$ & 60 & 763 & 298 & 1.71 & 304 \\
\hline $\mathbf{5}$ & 75 & 954 & 186 & 1.71 & 304 \\
\hline $\mathbf{6}$ & 100 (pure kinematic) & 1271 & 0 & 1.71 & 304 \\
\hline
\end{tabular}




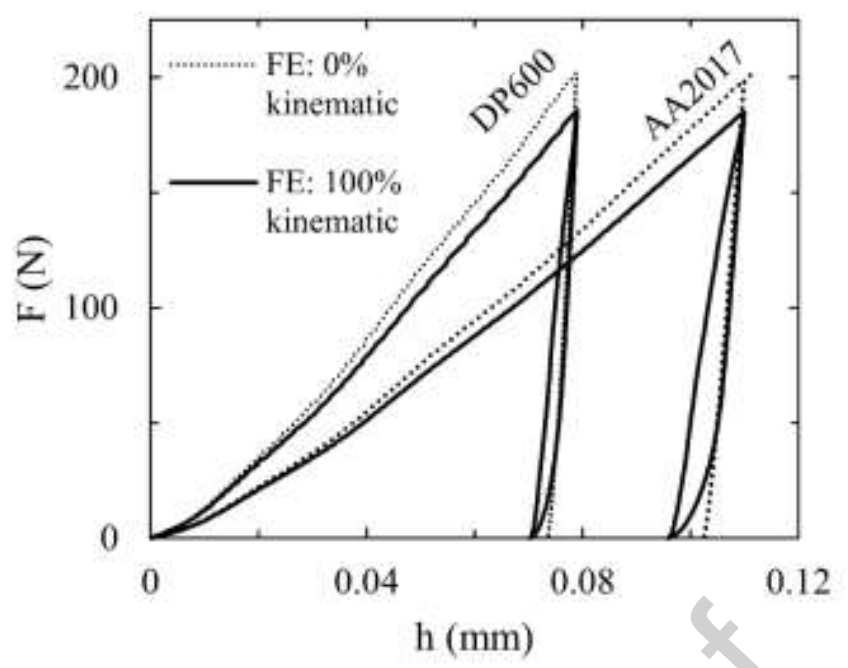

Fig. 5. Pure isotropic (0\% kinematic) and pure kinematic (100\% kinematic) indentation curves for both tested materials: loading and unloading-reloading curves (hysteresis loops) are represented. Tests are controlled by imposing a maximum indentation depth.

\subsection{Influence of hardening type on the indentation loading curve}

In this section, only DP600 results are presented. Similar results, obtained for AA2017, are presented in Appendix A. For the loading curve, kinematic hardening leads to a decrease in the resistance of the tested material to indenter penetration (fig. 5). To understand why kinematic hardening leads to a reduction in the penetration resistance of the material during a monotonic indentation test, the following numerical study of the deformation field under the indenter is carried out.

The numerical simulations show that the measured plastic strains in the vertical direction (PE22) are negative in the indenter/material contact zone: the material is being compressed by the indenter in this same direction (figs. 6-a and A1-a). In this same zone, the measured plastic strains in the horizontal direction (PE11) are positive: the material is under tension in this direction (figs. 6-b and A1-b). Out of the indenter/material contact zone, PE22 strains are positive. The horizontally displaced material, due to a relatively high contact angle, is under vertical tension (figs. 6-c and A1-c). In this same zone, PE11 
strains are negative. Due to the high contact angle, the material is horizontally compressed which creates a pile-up (figs. 6-d and A1-d). For indentation loading, the presented plastic strains in and out of the contact zone show that, for a given direction, some points of the indented zone undergo multi-paths loading.

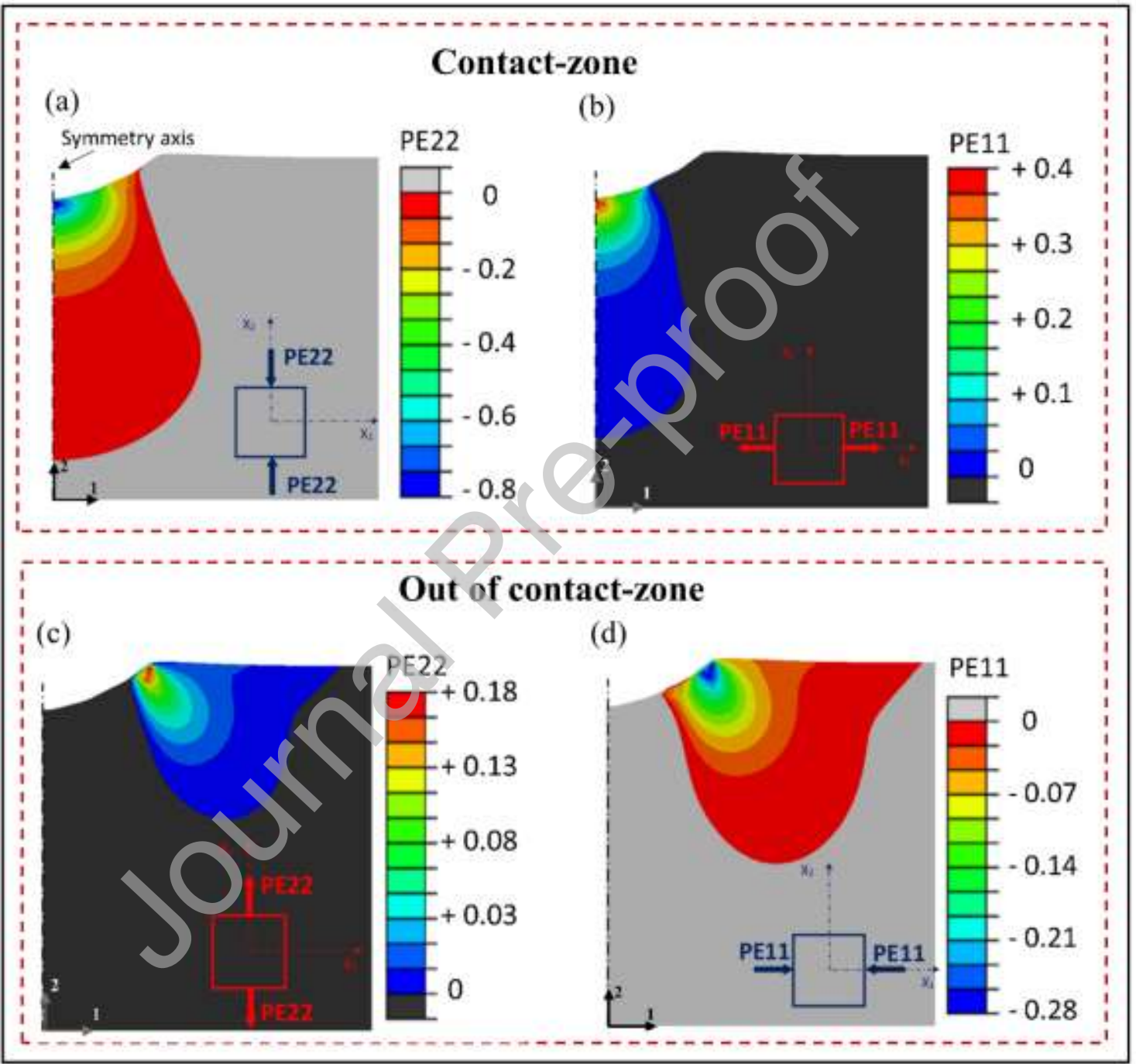

Fig. 6. DP600: Vertical (PE22) and horizontal (PE11) plastic strains obtained in and out of the indentation contact zone for a dimensionless penetration depth of $h / R=0.3$. (a) PE22 in the contact zone. (b) PE11 in the contact zone. (c) PE22 out of the contact zone. (d) PE11 out of the contact zone. 
Fig. 7 (a-b) show that for point " $P$ ", located at $x / R=0.25$ and $y / R=-0.127(R(\mathrm{~mm})$ being the approximated radius of the indenter tip), PE22 strain is positive for $h / R=0.08$ and then PE22 strain is negative for $\mathrm{h} / \mathrm{R}=0.3$. Point $P$ undergoes tension followed by compression in the vertical direction and compression followed by tension in the horizontal direction (fig. 8).

During indentation loading, the loading path of some indented zones is not monotonic. An important kinematichardening contribution results in a kind of a "Bauschinger effect" that softens the indentation loading curve. This study validates numerically the observations of Huber and Tsakmakis [52] and J.M. Collin etal. [53] showing the influence of kinematic hardening on the indentation loading curve. Our results obtained from indentation tests are also in agreement with those obtained from cyclic shear tests and cyclic compression-tensile tests. These tests show that kinematic hardening leads to a transient softening behaviour of various DP steels and Aluminum Alloys [66] [73].

Several studies aimed to identify the strain hardening laws of metallic materials using instrumented spherical indentation. Based on Hollomon's 2-parameters law, the identification of the hardening laws of 3 different materials was performed in [74] but the results were less accurate for an aluminum alloy of the 5000 series. Using the same law, EG Herbert et al. [75] were unable to correctly identify the hardening law of an AA6061. According to these studies, these errors are due to inaccuracies in the friction coefficient, FEM or analytical model adopted. In this study, it is shown that neglecting kinematic hardening by adopting simplifying laws such as Hollomon is one more reason to explain the discrepancy between the curves identified by IIT and those obtained by tensile testing. This is confirmed by other studies showing that AA6061 and more generally face-centered cubic aluminum show a significant 'Bauschinger Effect' in multi-axial loading due to the non-negligible presence of kinematic hardening [62] [63]. 

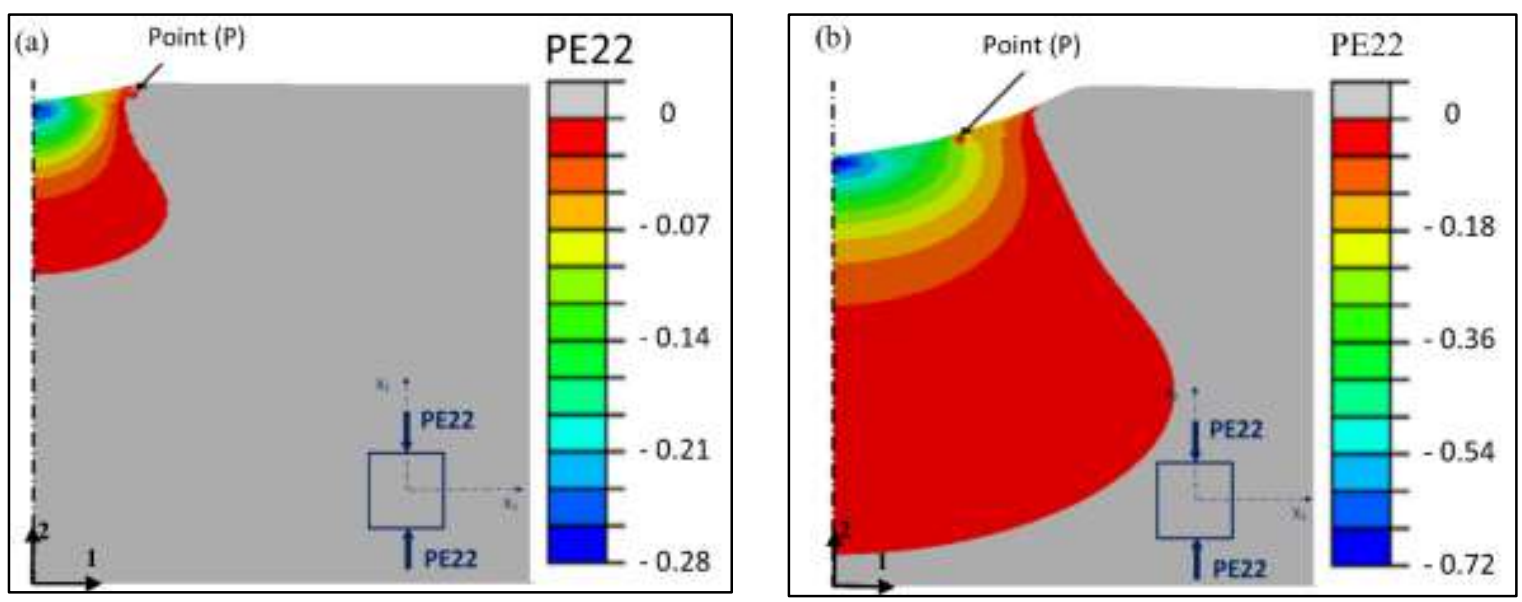

Fig. 7. Plastic strains in the vertical direction for point $P$ located at $x / R=0.25 ; y / R=-0.127$ : (a) Plastic strains are positive in the vertical direction (tension) for $h / R=0.08$, (b) Plastic strains are positive in the vertical direction (compression) for $\mathrm{h} / \mathrm{R}=0.3$. ( $\mathrm{h}(\mathrm{mm})$ being the indentation depth and $\mathrm{R}$ the approximate radius of the indenter).

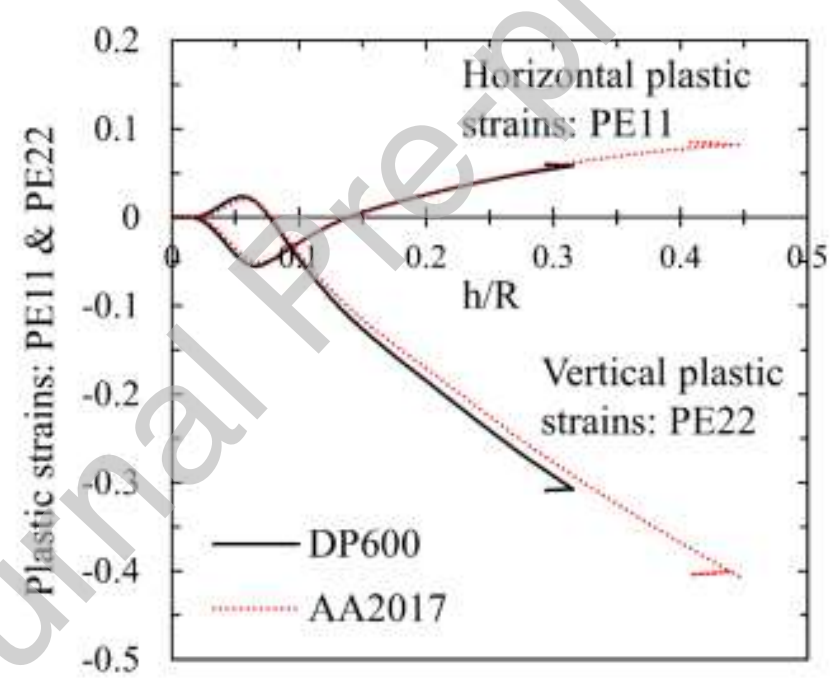

Fig. 8. Strain levels of point $P(x / R=0.25 ; y / R=-0.127)$ located in the indented zone during indentation loading for both tested materials as a function of $h / R$. During a loading indentation, horizontal plastic strains PE11 are negative for $\frac{h}{R}<0.14$ and then positive for $\frac{h}{R}>0.14$; Vertical plastic strains PE22 are positive for $\frac{h}{R}<0.075$ and then negative $\frac{h}{R}>0.075$.

\subsection{Influence of the hardening type on the hysteresis loop}

The hardening type influences the hysteresis loop. However, indentation curves aren't enough for determining the parameters of the Chaboche law due to the non-unicity of the obtained solution. Hereafter, a methodology, based on the hysteresis loop, is proposed for determining the contribution of 
each hardening type in the overall hardening behavior of the tested materials. In this section, results for both tested materials are presented. However, the corresponding figures for AA2017 are presented in Appendix B.

\subsubsection{Numerical study: characteristic ratio of the hysteresis loop}

A pseudo-material describing numerically the hardening behavior of a DC01 [18] is considered for this study. In the case of pure isotropic hardening, the corresponding Voce parameters are given in table 3.

Table 3 Voce parameters for pseudo-material

\begin{tabular}{cccc}
\hline & $\begin{array}{c}\sigma_{Y} \\
(\mathrm{MPa})\end{array}$ & $\mathbf{Q}(\mathrm{MPa})$ & $\mathbf{b}$ \\
\hline $\begin{array}{c}\text { Pseudo- } \\
\text { material 1 }\end{array}$ & 208 & 531 & 2.39 \\
\hline
\end{tabular}

The FE indentation model is used to obtain 2 indentation cyclic curves corresponding to pure isotropic hardening and pure kinematic hardening, respectively. $F / R^{2}(M P a)$ is presented as a function of $h / R$.

3 geometric parameters are considered (fig. 9 a-b):

$h_{r}:$ Residual indentation depth.

$h_{\max }$ : Maximum indentation depth before unloading. For each hysteresis loop, $h_{\max }$ is the same for both hardening types. Thus, this parameter is independent of the hardening type.

$h_{f}$ : Indentation depth obtained in the case of linear unloading (totally elastic unloading in the case of a flat punch). 

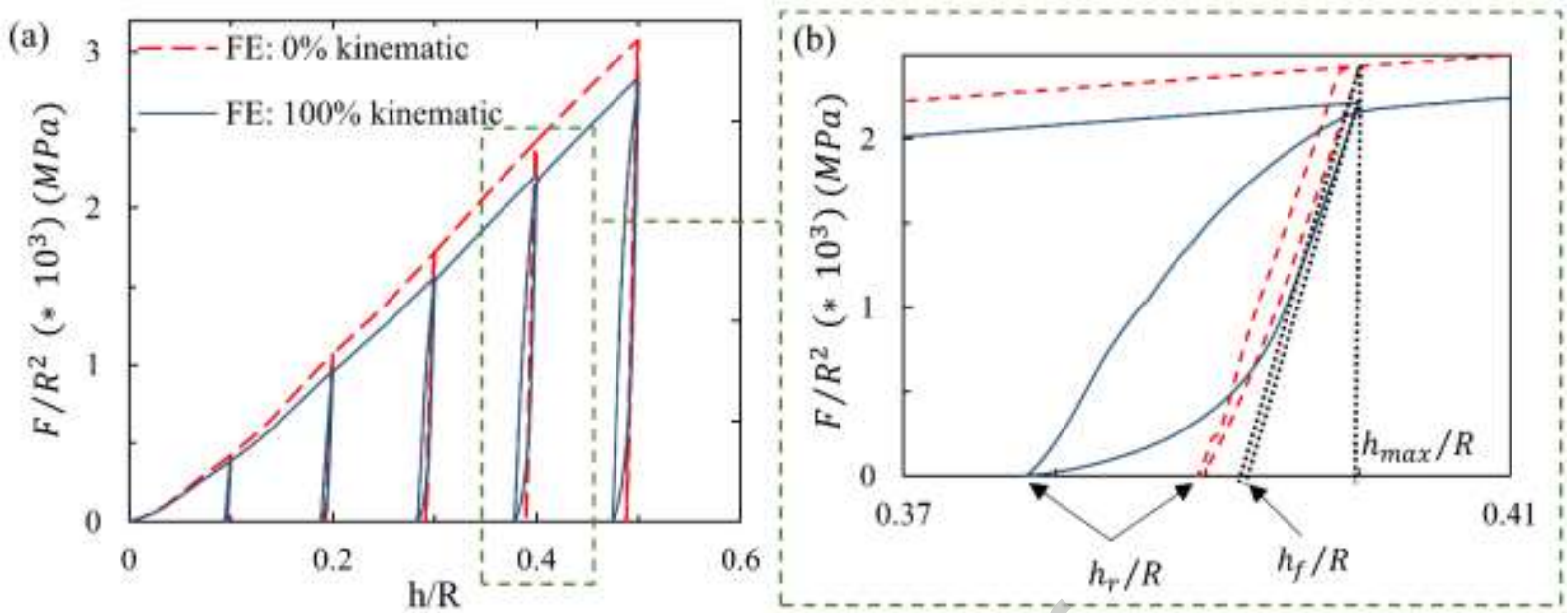

Fig. 9. (a) Pure isotropic and pure kinematic indentation curves for the studied pseudo-material represented as the evolution of $F / R^{2}(\mathrm{MPa})$ as a function of $h / R .5$ hysteresis loops are represented for each tested material for 5 different indentation depths $(h / R=0.1,0.2,0.3,0.4$ and 0.5$)$. (b) Hysteresis loops for pure isotropic and pure kinematic hardenings for $h / R=0.4$ and corresponding indentation depths: $h_{r}, h_{f}$ and $h_{\max }$.

$$
r=\frac{h_{f}-h_{r}}{h_{f}} \text { (eq. 18) is proposed as a new dimensionless geometrical ratio for evaluating the }
$$

contribution of each hardening type in the overall hardening law of the tested pseudo-material. ' $r$ ' is then calculated for different hardening type contributions and different indentation depths (fig. 10). Fig. 10 shows that indentation depth has no significant influence on this ratio. However, ' $r$ ' is strongly influenced by important kinematic hardening contributions.

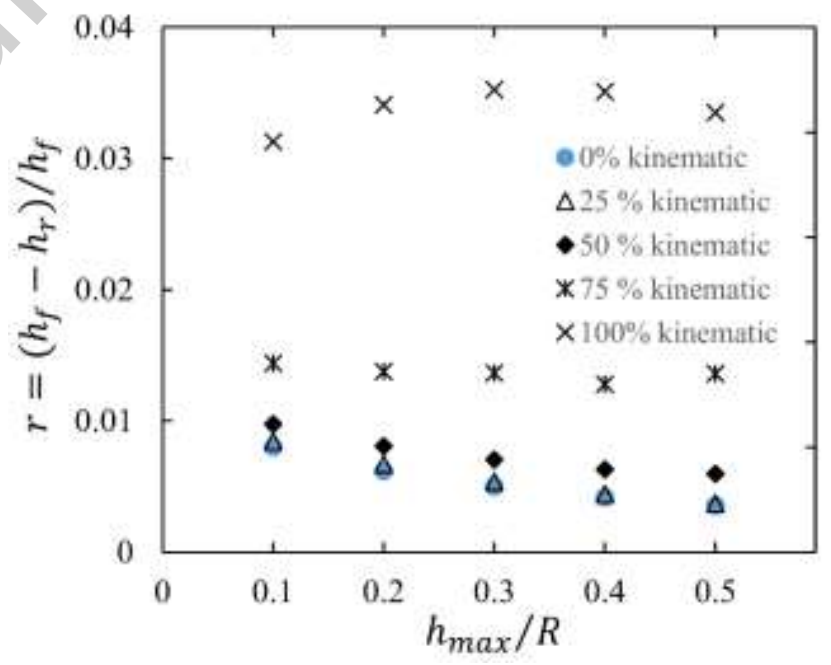


Fig. 10. $r=\frac{h_{f}-h_{r}}{h_{f}}$ values for different hardening type contributions and represented as a function of $h_{\max } / R$ (for each hysteresis loop represented in fig. 9).

It is noted that different ratios were previously proposed in the literature. The proposed ratios by Huber et Tsakmakis [52] are hereafter calculated for the presented pseudo-material and compared to ' $r$ '.

$W^{*}=\frac{W}{F_{\max }\left(h_{\max }-h_{r}\right)}$

$\Delta r=\frac{\left(h_{r}^{i s o}-h_{r}\right)}{h_{\max }}$

Where $W, W^{*}$ are work and dimensionless work of an unload-reload-cycle, respectively. $F_{\max }$ and $h_{\max }$ are respectively the maximum load and the maximum penetration depth obtained before the discharge. $h_{r}^{i s o}$ is the residual depth in the case of pure isotropic hardening.

$W^{*}$ and $\Delta r$ are calculated for two hardening type contributions (highly kinematic: $75 \%$ and purely kinematic: $100 \%$ ) and for different indentation depths. Fig. 11 shows the evolution of $\mathrm{W}^{*}$ and $\Delta r$ as a function of the hardening type: the more kinematic the hardening of the material is, the higher the values of ratios $\mathrm{W}^{*}$ and $\Delta r$ proposed by Huber et Tsakmakis [52]. However, fig. 11 shows that both ratios tend to increase with $h_{\max } / R$. As a function of $h_{\max } / R, W^{*}$ and $\Delta r$ are less stable than ' $r$ ' which justifies the use of the proposed ratio in the rest of the study. 


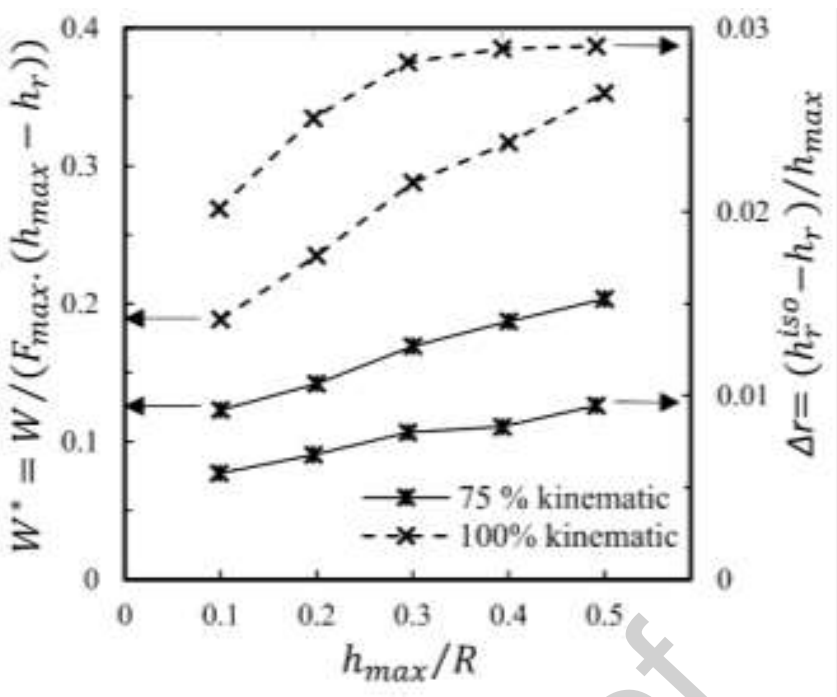

Fig. 11. Evolution of $\mathrm{W}^{*}$ and $\Delta r$ as a function of $h_{\max } / R$ (for each hysteres is loop presented in fig. 9) for important isotropic and kinematic hardening contributions: $75 \%$ kinematic hardening contribution and pure kinematic hardening (100\% kinematic).

\subsubsection{Application on real metal sheets}

FEA is used to obtain indentation hysteresis loops with varying hardening types using the values obtained from table 3 (fig. 12-a). ' $r^{\prime}$ is then calculated for the different hardening type contributions and represented in figs. 13 and B.3 as a function of $\frac{Q}{\frac{C}{\gamma}+Q}$ (ratio reflecting the contribution of isotropic hardening contribution in the overall hardening law). Afterward, the obtained numerical hysteresis loops are compared to the real experimental one (fig. 12-c \& 12 d). Concerning DP600, the experimental hysteresis loop is located between the ones obtained with $40 \%$ isotropic - $60 \%$ kinematic and 25\% isotropic - $75 \%$ kinematic hardening laws. Concerning AA2017, the experimental hysteresis loop is the closest to the 50\%-50\% hardening law. ' $r$ ' is then calculated for the experimental hysteresis loop and compared to the numerical ones (figs. 13 and B.3): $37 \%$ of isotropic hardening (thus $63 \%$ of kinematic hardening) is obtained for DP600 and $46 \%$ of isotropic hardening (thus 54\% of kinematic hardening) is obtained for AA2017. 


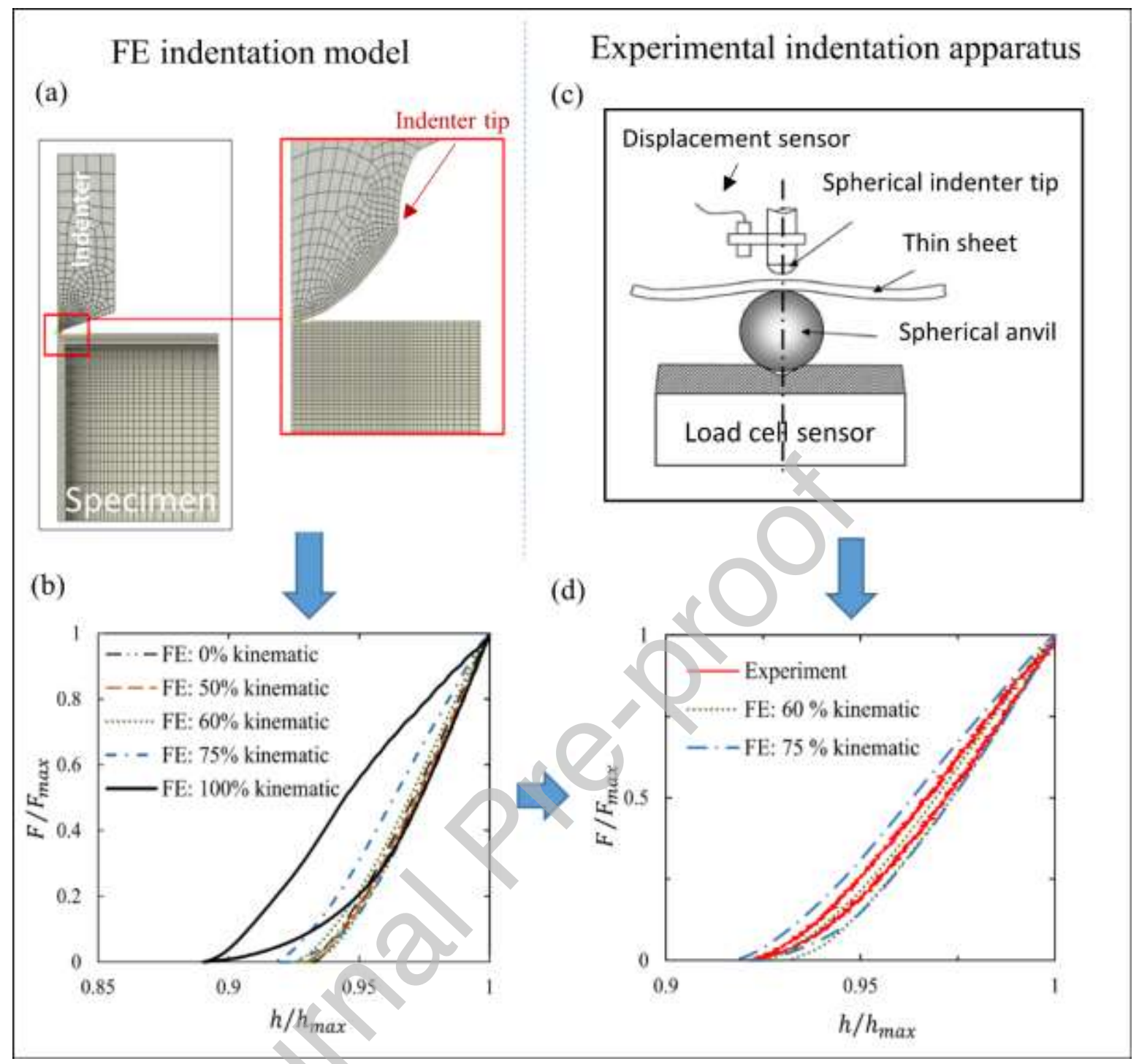

Fig. 12. (a) Indentation FE model used for numerical analysis. (b) Hysteresis loops obtained using FE for different kinematic hardening contributions. The obtained hysteresis loops correspond to DP600 a nd are represented as $F / F_{\text {max }}$ as a function of $h / h_{\text {max }}$ : standardization for indentation loading and depth. (c) Indentation experimental apparatus used for obtaining experimental indentation curves [67]. (d) Experimental hysteresis loop and nearest FE hysteresis loops (60\% kinematic and $75 \%$ kinematic hardening contributions) obtained for DP600. Hysteresis loops are represented as $F / F_{\text {max }}$ as a function of $h / h_{\text {max }}$ : standardization for indentation loading and depth. 


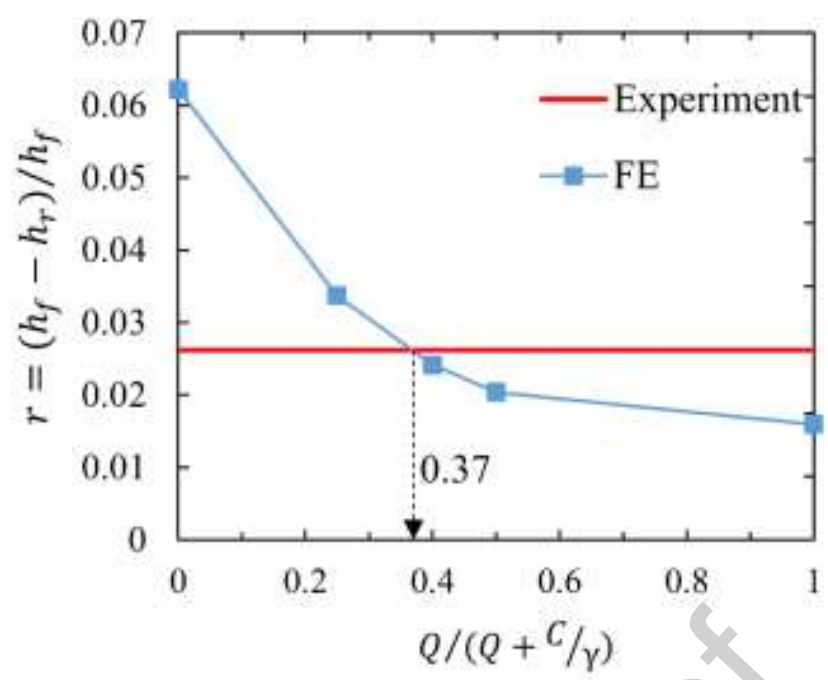

Fig. 13. $r=\frac{h_{f}-h_{r}}{h_{f}}$ calculated for experimental and numerical hysteresis loops for DP600. $r$ is represented as a function of $Q /(Q+C / \gamma)$ (ratio reflecting the contribution of isotropic hardening contribution in the overall hardening law). The $Q /(Q+C / \gamma)$ value corresponding to the intersection point between numerical and experimental $r$ values determines the contribution of each hardening type in the overall hardening law for DP600.

\subsubsection{Validation with cyclic shear tests}

Cyclic shear tests are carried out on the tested materials. The experimental curves are represented in figs 14 (a-b), and B.4. From these results, the reversed Cauchy stress-strain curves are determined and compared to the monotonic shear curve in fig. 15. DP600 and AA2017 show a distinct transient softening behavior and this corresponds to previous observations made on DP steel and Aluminum Alloys [66] [73]. The results obtained from the shear reversal tests are also in agreement with those obtained from the numerical indentation tests for which a decrease in penetration resistance is observed with an increase in kinematic hardening.

Based on the obtained $\tau-\gamma$ cyclic curves, the identification of Chaboche law parameters is performed using IAT. For obtaining comparable results to IIT results, $b=\gamma$ is also imposed in all the inverse analysis computations. The identification is carried out in 2 stages: a first 
identification using SIMPLEX algorithm followed by a second identification using BFGS algorithm based on the values of the parameters identified with the SIMPLEX method. 2 cases are studied: in the first one, only 2 cycles of the $\tau-\gamma$ curves are considered for optimization. In the second one, 3 cycles are considered. The identified numerical curves in both cases are compared to the experimental ones in figs 14 (a-b), and B.4. The obtained Chaboche parameters as well as $\frac{Q}{\frac{C}{\gamma}+Q}$ are presented in table $4.35 \%$ of isotropic hardening (thus $65 \%$ of kinematic hardening) is obtained for DP600 and $48 \%$ of isotropic hardening (thus $52 \%$ of kinematic hardening) is obtained for AA2017. These results are in perfect correlation with what was obtained using the indentation hysteresis loop.
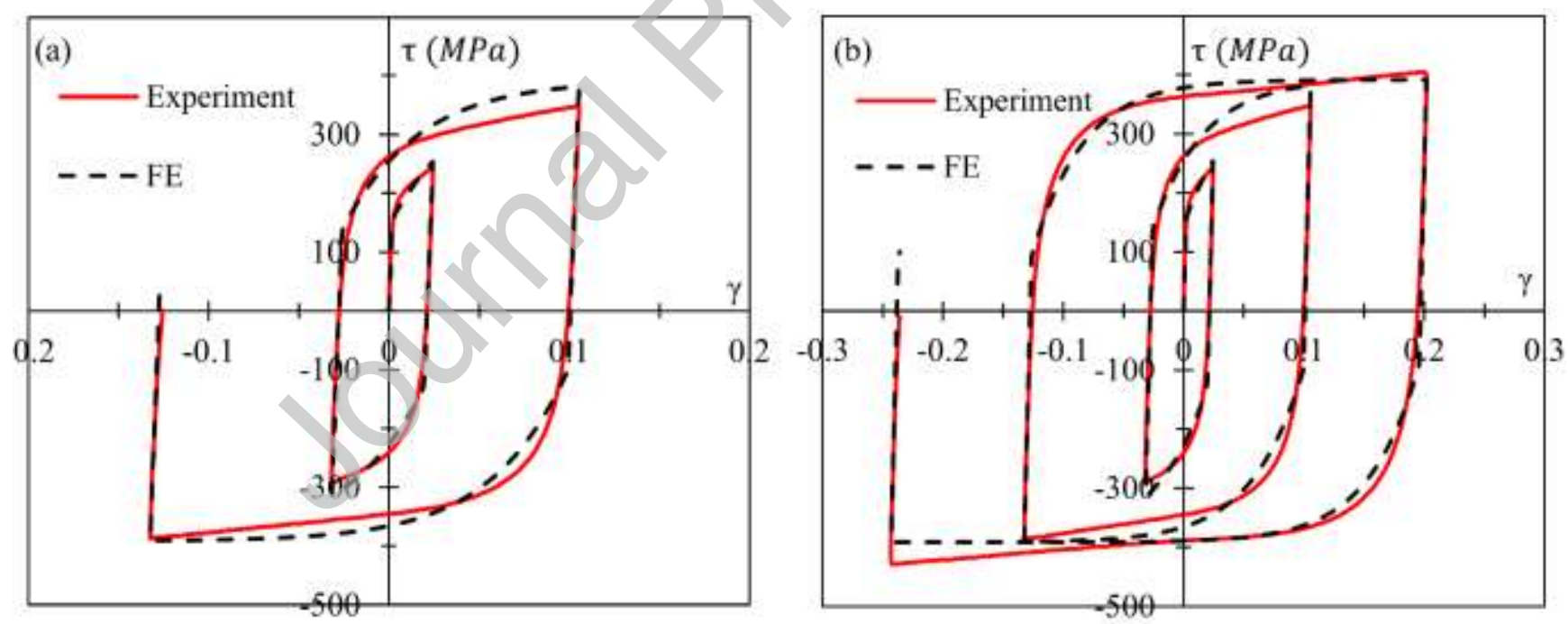

Fig. 14. Experimental and identified numerical shear cyclic curves for DP600 (a) 2 cycles; (b) 3 cycles. Experimental shear curves are obtained using the experimental apparatus presented in paragraph 3.1. Numerical shear cyclic curves are obtained using the inverse analysis technique. 5 parameters of the Chaboche law are identified taking into account the proposed hypothesis $b=\gamma$. 


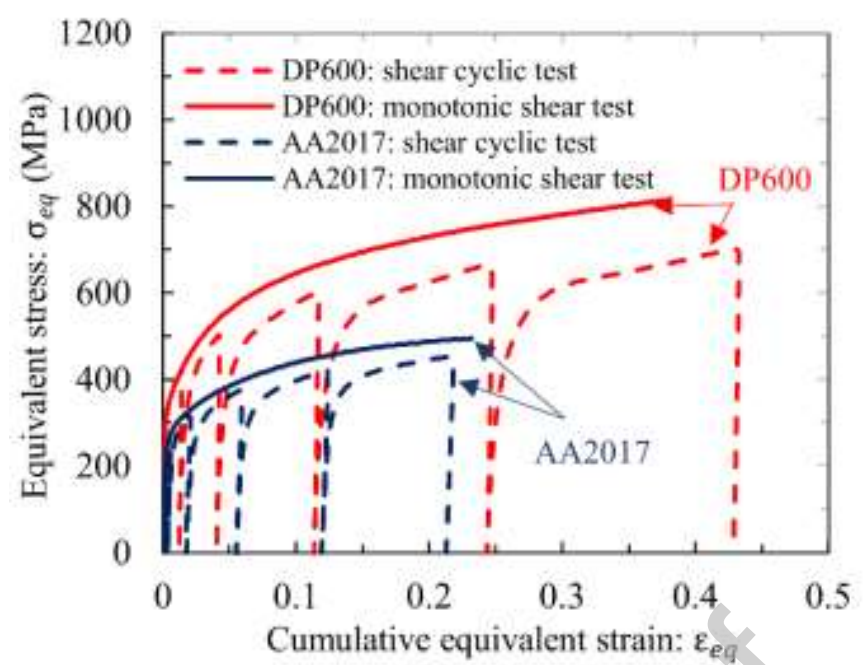

Fig. 15. Experimental shear cyclic curves compared to experimental monotonic shear curves for DP600 and AA2017. Shear cyclic curves are plotted (dashedlines) against cumulative equivalent strain.

Table 4 Identified Chaboche parameters for both materials using the shear cyclic curves and computation of the $\mathrm{Q} /(\mathrm{Q}+\mathrm{C} / \mathrm{y})$ relation

\begin{tabular}{|c|c|c|c|c|}
\hline & \multicolumn{2}{|c|}{ DP600 } & \multicolumn{2}{|c|}{ AA2017 } \\
\hline & 2 cycles & 3 cycles & 2 cycles & 3 cycles \\
\hline$\sigma_{Y}(\mathrm{MPa})$ & 278 & 272 & 264 & 247 \\
\hline $\mathrm{Q}(\mathrm{MPa})$ & 124 & 146 & 142 & 99 \\
\hline $\mathrm{C}(\mathrm{MPa})$ & 11641 & 11347 & 2010 & 5423 \\
\hline b & 50 & 43 & 12.93 & 50 \\
\hline$v$ & 50 & 43 & 12.93 & 50 \\
\hline$C / v$ & 233 & 261 & 155 & 108 \\
\hline$Q /(Q+C / \gamma)$ en $\%$ & 35 & 36 & 48 & 48 \\
\hline
\end{tabular}

\section{Conclusions}

This paper presents a phenomenological study of the influence of hardening type on the indentation curve for 2 different metal sheets: DP600 and AA2017.

Areas under the indenter undergo several loading paths during indenter penetration. Numerical results show that some material points undergo tension followed by compression in the vertical direction and compression followed by tension in the horizontal direction. For 
materials with a relatively high contribution of kinematic hardening in their hardening law, this leads to a softening of the indentation loading curve. For such materials, neglecting kinematic hardening in the mechanical characterization using IIT leads to considerable errors between the hardening laws characterized by IIT and those obtained by standard tensile and shear tests.

Kinematic hardening also influences the hysteresis loop. A novel approach based on a new depth ratio is proposed to determine the contribution of each hardening type in the hardening laws of both tested materials. The proposed depth ratio shows that DP600 presents $37 \%$ of isotropic hardening (thus $63 \%$ of kinematic hardening) and AA2017 presents $46 \%$ of isotropic hardening (thus $54 \%$ of kinematic hardening). The proposed approach is validated by comparing the obtained results with results obtained from cyclic shear testing. From the cyclic shear test $35 \%$ of isotropic hardening (thus $65 \%$ of kinematic hardening) is obtained for DP600 and $48 \%$ of isotropic hardening (thus 52\% of kinematic hardening) is obtained for AA2017. A perfect agreement is obtained between both approaches. For future works aiming to characterize elastoplastic parameters of materials based on IIT coupled to IAT, the obtained results from the proposed approach will be used to avoid the non-uniqueness problem. This will be a breakthrough for instrumented indentation where relatively complex hardening laws (ex: Chaboche) are to be determined.

\section{Declaration of Competing Interest}

None.

\section{Acknowledgment}

This work has been financially supported by "ESI-Group", "la Région Bretagne" and "Rennes métropole". 


\section{Nomenclature and abbreviations}

DD: Diagonal Direction

e: Thickness of the specimen $(\mathrm{mm})$

$E_{1}$ : Cost function used in the case of shear tests

$\boldsymbol{E}_{2}$ : Cost function used in the case of Instrumented indentation tests

$\varepsilon_{e q}$ : Equivalent strain calculated using VonMises criterion

$\varepsilon_{p}^{e q}:$ Equivalent plastic strain

$\boldsymbol{\varepsilon}_{\boldsymbol{p}}^{\dot{\boldsymbol{q}} \boldsymbol{q}}$ : Equivalent plastic strain rate which corresponds to $\dot{\lambda}$

$\dot{\overline{\varepsilon_{p}}}$ : Plastic part of the strain rate tensor

F: Measured force (N)

$\boldsymbol{F}_{\text {max }}$ : maximum load obtained before the discharge $(\mathrm{N})$

$\gamma$ : Shear strain

$\gamma_{\text {xyexp }}$ : Experimental shear strain

$\gamma_{\text {xynum }}$ : Numerical shear strain

$\boldsymbol{h}$ : Indentation depth $(\mathrm{mm})$

$\boldsymbol{h}_{\boldsymbol{f}}$ : Indentation depth obtained in the case of linear unloading $(\mathrm{mm})$

$\boldsymbol{h}_{\text {max }}$ : Maximum indentation depth before unloading $(\mathrm{mm})$

$\boldsymbol{h}_{\boldsymbol{r}}:$ Residual indentation depth $(\mathrm{mm})$

$\boldsymbol{h}_{r}^{i s o}$ : Residual depth in the case of pure isotropic hardening $(\mathrm{mm})$

IAT: Inverse Analysis Technique

IIT: Instrumented Indentation Technique

$\boldsymbol{J}_{\mathbf{2}}(\overline{\overline{\boldsymbol{\sigma}}}-\overline{\bar{X}})$ : Equivalent Von-Mises stress with respect to the backstress tensor $\overline{\bar{X}}$

L: Total length of shear specimens $(\mathrm{mm})$

$\lambda$ and $\mu$ : Lamé's coefficients $\dot{\lambda}$ : Positive plastic flow multiplier

$\Omega$ : Strain path used to track the accumulation of plasticity

PE11: plastic strains in the horizontal direction

PE22: plastic strains in the vertical direction

R: Scalar valued variable describing effects of the isotropic hardening ( $\mathrm{MPa}$ )

$\boldsymbol{r}$ : proposed dimensionless geometrical ratio for evaluating the contribution of each hardening type in the overall hardening law.

$\boldsymbol{R}$ : Approximated radius of the indenter $(\mathrm{mm})$

RD: Rolling Direction

$\overline{\bar{S}}$ : Deviatoric stress tensor

$\overline{\overline{\boldsymbol{\sigma}}}$ : Stress tensor

$\sigma_{e q}:$ Equivalent stress calculated using VonMises criterion (MPa)

$\sigma_{Y}:$ Yield stress (MPa)

$\boldsymbol{\sigma}_{\boldsymbol{Y}-\boldsymbol{V}}(M P a), \boldsymbol{Q}_{\boldsymbol{V}}(M P a)$ and $\boldsymbol{b}_{\boldsymbol{V}}: \quad$ Voce parameters identified in [18].

$\boldsymbol{\sigma}_{\boldsymbol{Y}}(M P a), \boldsymbol{Q}(M P a), \boldsymbol{C}(M P a), \boldsymbol{b}$ and $\boldsymbol{\gamma}$ :

Chaboche parameters describing the mixed hardening behavior law.

TD: Transversal Direction

$\tau$ : Shear stress (MPa)

$\tau_{\text {xyexp }}$ : Experimental shear stress (MPa)

$\boldsymbol{\tau}_{\text {xynum: }}$ Numerical shear stress (MPa)

$\boldsymbol{W}$ : Work of an unload-reload-cycle

$W^{*}$ : Dimensionless work of an unload-reloadcycle

$\overline{\bar{X}}$ : Kinematic hardening tensor (backstress tensor)

$\overline{\overline{X_{d}}}$ : Deviatoric part of the backstress tensor 


\section{References}

[1] C. U. Shepard, A Treatise on Mineralogy. C.U. Shepard, 1857.

[2] H. Hertz, Miscellaneous Papers. Macmillan, 1896.

[3] J. A. Brinell, "Way of determining the hardness of bodies and some applications of the same," Teknisk Tidskrift, vol. 5, p. 69, 1900.

[4] D. Tabor, The Hardness of Metals. OUP Oxford, 2000.

[5] I. M. Hutchings, "The contributions of David Tabor to the science of indentation hardness," Journal of Materials Research, vol. 24, no. 3, pp. 581-589, Mar. 2009, doi: 10.1557/jmr.2009.0085.

[6] W. C. Oliver and G. M. Pharr, "An improved technique for determining hardness and elastic modulus using load and displacement sensing indentation experiments," Journal of materials research, vol. 7, no. 6, pp. 1564-1583, 1992.

[7] A. E. Giannakopoulos and S. Suresh, "Determination of elastoplastic properties by instrumented sharp indentation," Scripta materialia, vol. 40, no. 10, pp. 1191-1198, 1999.

[8] S. Bec, A. Tonck, J.-M. Georges, E. Georges, and J.-L. Loubet, "Improvements in the indentation method with a surface force apparatus," Philosophical Magazine A, vol. 74, no. 5, pp. 1061-1072, 1996.

[9] J. L. Loubet, J. M. Georges, and G. Meille, "Vickers indentation curves of elastoplastic materials," in Microindentation Techniques in Materials Science and Engineering, ASTM International, 1985.

[10] J. L. Loubet, J. M. Georges, O. Marchesini, and G. Meille, "Vickers indentation curves of magnesium oxide (MgO)," 1984.

[11] M. Zhao, N. Ogasawara, N. Chiba, and X. Chen, "A new approach to measure the elasticplastic properties of bulk materials using spherical indentation," Acta Materialia, vol. 54, no. 1, pp. 23-32, 2006.

[12] Y. P. Cao and J. Lu, "A new method to extract the plastic properties of metal materials from an instrumented spherical indentation loading curve," Acta materialia, vol. 52, no. 13, pp. 4023-4032, 2004.

[13] H. Lee, J. Haeng Lee, and G. M. Pharr, "A numerical approach to spherical indentation techniques for material property evaluation," Journal of the Mechanics and Physics of Solids, vol. 53, no. 9, pp. 2037-2069, Sep. 2005, doi: 10.1016/j.jmps.2005.04.007.

[14] J. E. Campbell, R. P. Thompson, J. Dean, and T. W. Clyne, "Experimental and computational issues for automated extraction of plasticity parameters from spherical indentation," Mechanics of Materials, vol. 124, pp. 118-131, 2018.

[15] B. Bhushan and V. N. Koinkar, "Nanoindentation hardness measurements using atomic force microscopy," Applied physics letters, vol. 64, no. 13, pp. 1653-1655, 1994.

[16] Y. Huang, F. Zhang, K. C. Hwang, W. D. Nix, G. M. Pharr, and G. Feng, "A model of size effects in nano-indentation," Journal of the Mechanics and Physics of Solids, vol. 54, no. 8, pp. 1668-1686, 2006.

[17] C.-M. Sanchez-Camargo, A. Hor, and C. Mabru, "A robust inverse analysis method for elastoplastic behavior identification using the true geometry modeling of Berkovich indenter," International Journal of Mechanical Sciences, vol. 171, p. 105370, 2020.

[18] M. Idriss, O. Bartier, G. Mauvoisin, and X. Hernot, "Determining the stress level of monotonic plastically pre-hardened metal sheets using the spherical instrumented indentation technique," Journal of Mechanical Science and Technology, vol. 33, no. 1, pp. 183-195, 2019. 
[19] C. Moussa, O. Bartier, G. Mauvoisin, X. Hernot, J.-M. Collin, and G. Delattre, "Experimental and numerical investigation on carbonitrided steel characterization with spherical indentation," Surface and Coatings Technology, vol. 258, pp. 782-789, 2014.

[20] J.-M. Collin, G. Mauvoisin, and P. Pilvin, "Materials characterization by instrumented indentation using two different approaches," Materials \& Design, vol. 31, no. 1, pp. 636640, 2010.

[21] E. Broitman, "Indentation hardness measurements at macro-, micro-, and nanoscale: a critical overview," Tribology Letters, vol. 65, no. 1, p. 23, 2017.

[22] M. M. Chaudhri, "Subsurface strain distribution around Vickers hardness indentations in annealed polycrystalline copper," Acta Materialia, vol. 46, no. 9, pp. 3047-3056, May 1998, doi: 10.1016/S1359-6454(98)00010-X.

[23] L. Rabemananjara, X. Hernot, G. Mauvoisin, A. Gavrus, and J.-M. Collin, "Formulation of a representative plastic strain and representative plastic strain rate by using a conical indentation on a rigid visco-plastic material," Materials \& Design, vol. 68, pp. 207-214, 2015.

[24] P.-L. Larsson, "Investigation of sharp contact at rigid-plastic conditions," International journal of mechanical sciences, vol. 43, no. 4, pp. 895-920, 2001.

[25] S. Kucharski and Z. Mróz, "Identification of yield stress and plastic hardening parameters from a spherical indentation test," International Journal of Mechanical Sciences, vol. 49, no. 11, pp. 1238-1250, 2007.

[26] M. Kim, K. P. Marimuthu, J. H. Lee, and H. Lee, "Spherical indentation method to evaluate material properties of high-strength materia is," International Journal of Mechanical Sciences, vol. 106, pp. 117-127, Feb. 2016, doi: 10.1016/j.jmecsci.2015.12.008.

[27] Y. Li, P. Stevens, M. Sun, C. Zhang, and W. Wang, 'Improvement of predicting mechanical properties from spherical indentation test," International Journal of Mechanical Sciences, vol. 117, pp. 182-196, Oct. 2016, doi: 10.1016/j.ijmecsci.2016.08.019.

[28] N. Yu, A. A. Polycarpou, and T. F. Conry, "Tip-radius effect in finite element modeling of sub-50 nm shallow nanoindentation," Thin solid films, vol. 450, no. 2, pp. 295-303, 2004.

[29] W. Chen, M. Li, T. Zhang, Y.-T. Cheng, and C.-M. Cheng, "Influence of indenter tip roundness on hardness behavior in nanoindentation," Materials Science and Engineering: $A$, vol. 445-446, pp. 323-327, Feb. 2007, doi: 10.1016/j.msea.2006.09.050.

[30] J. Krier, J. Breuils, L. Jacomine, and H. Pelletier, "Introduction of the real tip defect of Berkovich indenter to reproduce with FEM nanoindentation test at shallow penetration depth," Journal of Materials Research, vol. 27, no. 1, pp. 28-38, Jan. 2012, doi: 10.1557/jmr.2011.387.

[31] M. Idriss, O. Bartier, G. Mauvoisin, C. Moussa, E. Gazo Hanna, and X. Hernot, "Determination of the plastic strain by spherical indentation of uniaxially deformed sheet metals," in Key Engineering Materials, 2015, vol. 651, pp. 950-956.

[32] C. Moussa, X. Hernot, O. Bartier, G. Delattre, and G. Mauvoisin, "Evaluation of the tensile properties of a material through spherical indentation: definition of an average representative strain and a confidence domain," Journal of Materials Science, vol. 49, no. 2, pp. 592-603, 2014.

[33] R. E. Miller, "A continuum plasticity model for the constitutive and indentation behaviour of foamed metals," International Journal of Mechanical Sciences, vol. 42, no. 4, pp. 729754, Apr. 2000, doi: 10.1016/S0020-7403(99)00021-1. 
[34] S. H. Kim, B. W. Lee, Y. Choi, and D. Kwon, "Quantitative determination of contact depth during spherical indentation of metallic materials-A FEM study," Materials Science and Engineering: A, vol. 415, no. 1, pp. 59-65, Jan. 2006, doi: 10.1016/j.msea.2005.08.217.

[35] J.-Y. Kim, K.-W.Lee, J.-S. Lee, and D. Kwon, "Determination of tensile properties by instrumented indentation technique: Representative stress and strain approach," Surface and Coatings Technology, vol. 201, no. 7, pp. 4278-4283, Dec. 2006, doi: 10.1016/j.surfcoat.2006.08.054.

[36] Y. Cao, X. Qian, and N. Huber, "Spherical indentation into elastoplastic materials: Indentation-response based definitions of the representative strain," Materials Science and Engineering: A, vol. 454, pp. 1-13, 2007.

[37] J. H. Lee, T. Kim, and H. Lee, "A study on robust indentation techniques to evaluate elastic-plastic properties of metals," International Journal of Solids and Structures, vol. 47, no. 5, pp. 647-664, 2010.

[38] M. Beghini, L. Bertini, and V. Fontanari, "Evaluation of the stress-strain curve of metallic materials by spherical indentation," International Journal of Solids and Structures, vol. 43, no. 7, pp. 2441-2459, Apr. 2006, doi: 10.1016/j.jisolstr.2005.06.068.

[39] M. Yetna N'Jock, F. Roudet, M. Idriss, O. Bartier, and D. Chicot, "Work-of-indentation coupled to contact stiffness for calculating elastic modulus by instrumented indentation," Mechanics of Materials, vol. 94, pp. 170-179, Mar. 2016, doi: 10.1016/j.mechmat.2015.12.003.

[40] Y. Gu, T. Nakamura, L. Prchlik, S. Sampath, and J. Wallace, "Micro-indentation and inverse analysis to characterize elastic-plastic graded materials," Materials Science and Engineering: A, vol. 345, no. 1-2, pp 223-233, 2003.

[41] C. K. Moy, M. Bocciarelli, S. P. Ringer, and G. Ranzi, "Identification of the material properties of $\mathrm{Al} 2024$ alloy by means of inverse analysis and indentation tests," Materials Science and Engineering: A, vol. 529, pp. 119-130, 2011.

[42] T. Nakamura and Y. Gu, "Identification of elastic-plastic anisotropic parameters using instrumented indentation and inverse analysis," Mechanics of materials, vol. 39, no. 4, pp. 340-356, 2007.

[43] N. Chollacoop, M. Dao, and S. Suresh, "Depth-sensing instrumented indentation with dual sharp indenters," Acta Materialia, vol. 51, no. 13, pp. 3713-3729, Aug. 2003, doi: 10.1016/S1359-6454(03)00186-1.

[44] H. Lan and T. A. Venkatesh, "On the uniqueness and sensitivity issues in determining the elastic and plastic properties of power-law hardening materials through sharp and spherical indentation," Philosophical Magazine, vol. 87, no. 30, pp. 4671-4729, 2007.

[45] P. Fernandez-Zelaia, V. R. Joseph, S. R. Kalidindi, and S. N. Melkote, "Estimating mechanical properties from spherical indentation using Bayesian approaches," Materials \& Design, vol. 147, pp. 92-105, 2018.

[46] J. J. Kang, A. A. Becker, and W. Sun, "Determining elastic-plastic properties from indentation data obtained from finite element simulations and experimental results," International Journal of Mechanical Sciences, vol. 62, no. 1, pp. 34-46, Sep. 2012, doi: 10.1016/j.ijmecsci.2012.05.011.

[47] E. VOCE, "The Relationship between Stress and Strain for Homogeneous Deformation," Journal of the Institute of Metals, vol. 74, pp. 537-562, 1948.

[48] N. Huber and C. Tsakmakis, "Determination of constitutive properties fromspherical indentation data using neural networks. Part i: the case of pure kinematic hardening in 
plasticity laws," Journal of the Mechanics and Physics of Solids, vol. 47, no. 7, pp. 1569$1588,1999$.

[49] N. Huber and C. Tsakmakis, "Determination of constitutive properties fromspherical indentation data using neural networks. Part ii: plasticity with nonlinear isotropic and kinematichardening," Journal of the Mechanics and Physics of Solids, vol. 47, no. 7, pp. 1589-1607, 1999.

[50] N. Huber and Ch. Tsakmakis, "A Finite Element Analys is of the Effect of Hardening Rules on the Indentation Test," Journal of Engineering Materials and Technology, vol. 120, no. 2, pp. 143-148, Apr. 1998, doi: 10.1115/1.2807003.

[51] N. Huber and C. Tsakmakis, "Experimental and theoretical investigation of the effect of kinematic hardening on spherical indentation," Mechanics of materials, vol. 27, no. 4, pp. 241-248, 1998.

[52] N. Huber and C. Tsakmakis, "A finite element analysis of the effect of hardening rules on the indentation test," 1998.

[53] J.-M. Collin, T. Parenteau, G. Mauvoisin, and P. Pilvin, "Material parameters identification using experimental continuous spherical indentation for cyclic hardening," Computational Materials Science, vol. 46, no. 2, pp. 333-338, Aug. 2009, doi: 10.1016/j.commatsci.2009.03.016.

[54] I. Pane and E. Blank, "Role of plasticity on indentation behavior: Relations between surface and subsurface responses," International journal of solids and structures, vol. 43, no. 7-8, pp. 2014-2036, 2006.

[55] A. S. Shedbale, I. V. Singh, B. K. Mishra, and K. Sharma, "Evaluation of mechanical properties using spherical ball indentation and coupled finite element-element-free galerkin approach," Mechanics of Advanced Materials and Structures, vol. 23, no. 7, pp. 832-843, 2016.

[56] J. Han, K. P. Marimuthu, S. Koo, and H. Lee, "Numerical implementation of modified Chaboche kinematic hardening model for multiaxial ratcheting," Computers \& Structures, vol. 231, p. 106222, 2020 .

[57] J. Lemaitre and J.-L. Chaboche, Mechanics of Solid Materials. Cambridge University Press, 1994.

[58] H. M. Sajjad, H. ul Hassan, M. Kuntz, B. J. Schäfer, P. Sonnweber-Ribic, and A. Hartmaier, "Inverse Method to Determine Fatigue Properties of Materials by Combining Cyclic Indentation and Numerical Simulation," 2020.

[59] P. J. Armstrong and C. O. Frederick, A mathematical representation of the multiaxial Bauschinger effect, vol. 731. Central Electricity Generating Board [and] Berkeley Nuclear Laboratories ..., 1966.

[60] J.-L. Chaboche, "Time-independent constitutive theories for cyclic plasticity," International Journal of plasticity, vol. 2, no. 2, pp. 149-188, 1986.

[61] J. Cao, W. Lee, H. S. Cheng, M. Seniw, H.-P. Wang, and K. Chung, "Experimental and numerical investigation of combined isotropic-kinematic hardening behavior of sheet metals," International Journal of Plasticity, vol. 25, no. 5, pp. 942-972, 2009.

[62] R. R. McCullough, J. B. Jordon, P. G. Allison, D. J. Bammann, L. Garcia, and T. W. Rushing, "Characterization of the Bauschinger effect in an extruded aluminum alloy," Strength, Fracture and Complexity, vol. 10, no. 3-4, pp. 175-190, 2017. 
[63] J. B. Jordon, M. F. Horstemeyer, K. Solanki, and Y. Xue, "Damage and stress state influence on the Bauschinger effect in aluminum alloys," Mechanics of Materials, vol. 39, no. 10, pp. 920-931, 2007.

[64] E. ISO, "6892-1. Metallic materials-Tensile testing-Part 1: Method of test at room temperature," International Organization for Standardization, 2009.

[65] S. Thuillier and P.-Y. Manach, "Comparison of the work-hardening of metallic sheets using tensile and shear strain paths," International Journal of Plasticity, vol. 25, no. 5, pp. 733$751,2009$.

[66] J. Carbonniere, S. Thuillier, F. Sabourin, M. Brunet, and P.-Y. Manach, "Comparison of the work hardening of metallic sheets in bending-unbending and simple shear," International Journal of Mechanical Sciences, vol. 51, no. 2, pp. 122-130, 2009.

[67] G. Mauvoisin, "Continuous or instrumented indentation device with convex bearing surface and use thereof, particularly for metal sheet indentation. France Patent (2008) FR2008005619, International Patent WO2010/029179 (A1) // EP 2335044 B1 // US 2011/0174036 A1.," US8621903B2, Jan. 07, 2014.

[68] 'ISO-14577-1, Part 1: Test Method, Switzerland: Geneva, 2002."

[69] P. O. Maruschak, I. B. Okipnyi, L. Y. Poberezhnyi, and E. V. Maruschak, "Study of heatresistant steel strain hardening by indentation," Metallurgist, vol. 56, no. 11, pp. 946-951, 2013.

[70] V. M. Matyunin, N. Abusaif, and A. Y. Marchenkov, "Influence of grains and grain boundaries on hardness values," in Journal of Physics: Conference Series, 2019, vol. 1399, no. 4, p. 044002.

[71] M. Chausov, P. Maruschak, A. Pylypenko, and O. Prentkovskis, "Influence of Changes in Structural and Mechanical Condition of Aluminum Alloys Caused by Impact-Oscillatory Loading on Their Fatigue Life," in International Conference on Reliability and Statistics in Transportation and Communication, 2019, pp. 491-499.

[72] M. A. G. Calle, L. M. Mazzariol, and M. Alves, "Strain rate sensitivity assessment of metallic materials by mechanical indentation tests," Materials Science and Engineering: A, vol. 725, pp. 274-282, 2018.

[73] M. Weiss, A. Kupke, P. Y. Manach, L. Galdos, and P. D. Hodgson, "On the Bauschinger effect in dual phase steel at high levels of strain," Materials Science and Engineering: A, vol. 643, pp. 127-136, 2015.

[74] B. Taljat, T. Zacharia, and F. Kosel, "New analytical procedure to determine stress-strain curve from spherical indentation data," International Journal of Solids and Structures, vol. 35, no. 33, pp. 4411-4426, 1998.

[75] E. G. Herbert, G. M. Pharr, W. C. Oliver, B. N. Lucas, and J. L. Hay, "On the measurement of stress-strain curves by spherical indentation," Thin solid films, vol. 398, pp. 331-335, 2001. 


\section{Appendix A: AA2017}

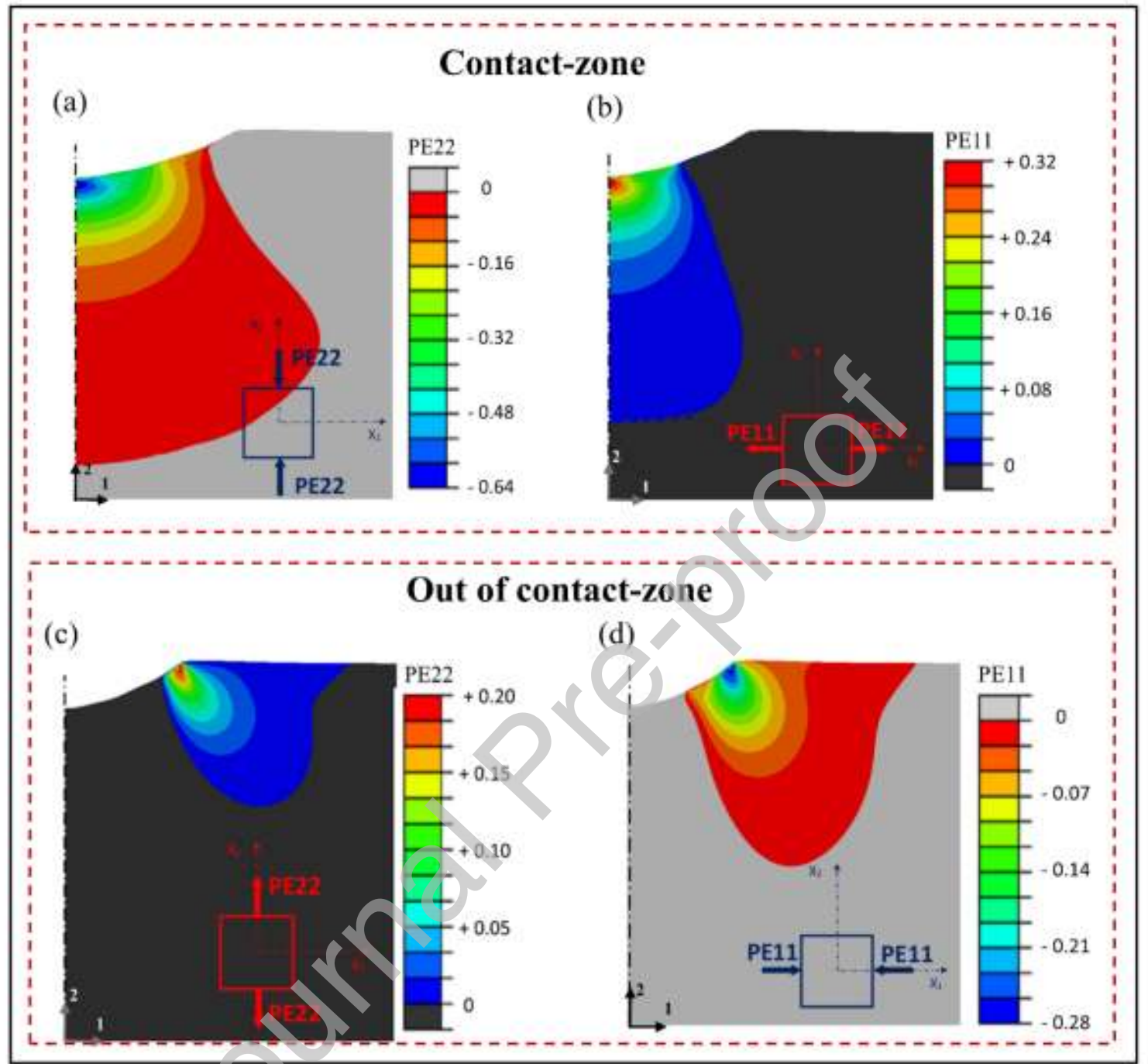

Fig. A.1. AA2017: Vertical (PE22) and horizontal (PE11) plastic strains obtained in and out of the indentation contact zone for a dimensionless penetration depth of $h / R=0.3$. (a) PE22 in the contact zone. (b) PE11 in the contact zone. (c) PE22 out of the contact zone. (d) PE11 out of the contact zone. 


\section{Appendix B: AA2017}

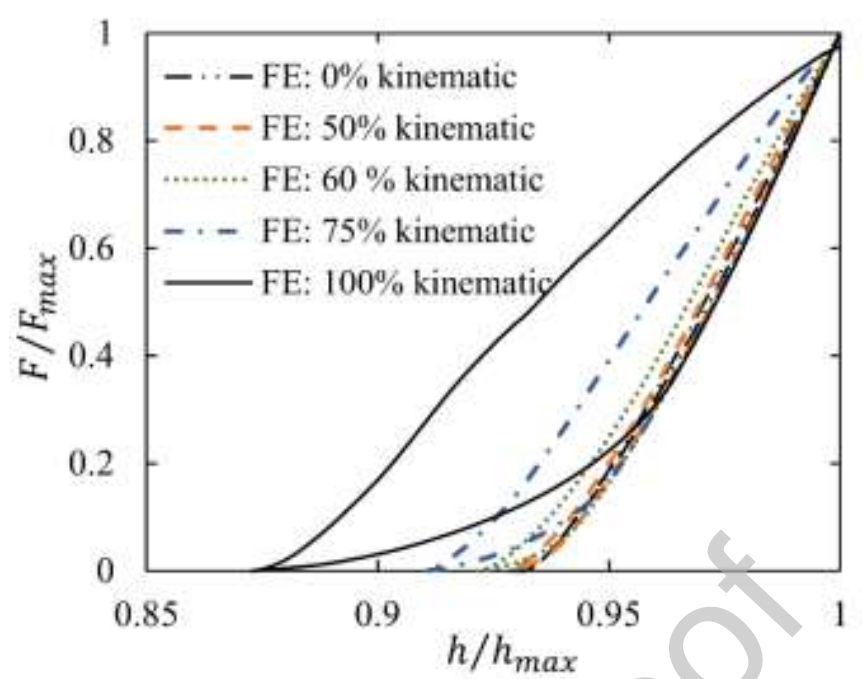

Fig. B.1. Hysteresis loops obtained using FE for different kinematic hardening contributions. The obtai ned hysteresis loops correspond to DP600 and are represented as $F / F_{\max }$ as a function of $h / h_{\text {max }}$ : standardization for indentation loading and depth.

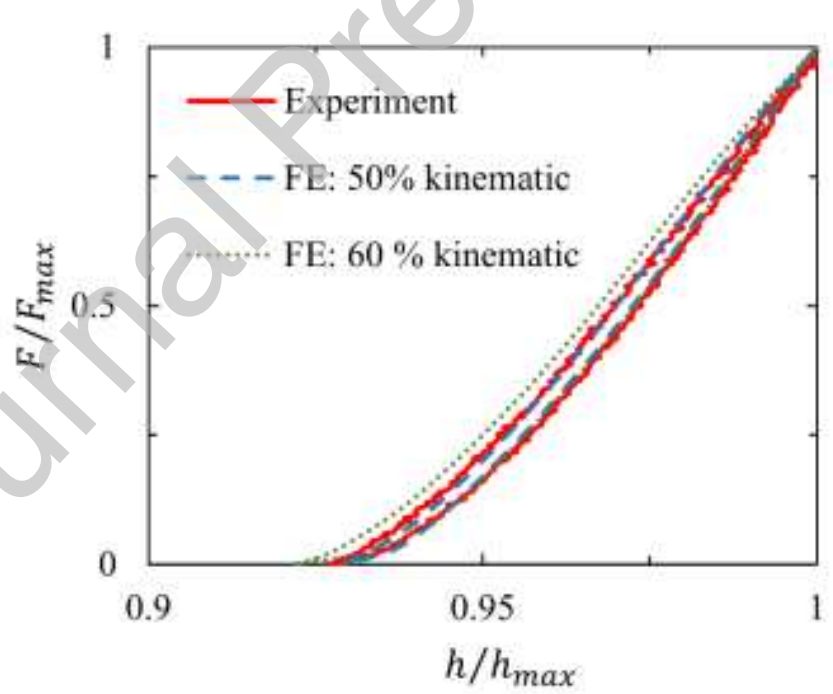

Fig. B.2. Experimental hysteresis loop and nearest FE hysteresis loops (60\% kinematic and 75\% kinematic hardening contributions) obtained for AA2017. Hysteresis loops are represented as $F / F_{\text {max }}$ as a function of $h / h_{\max }:$ standardization for indentation loading and depth. 


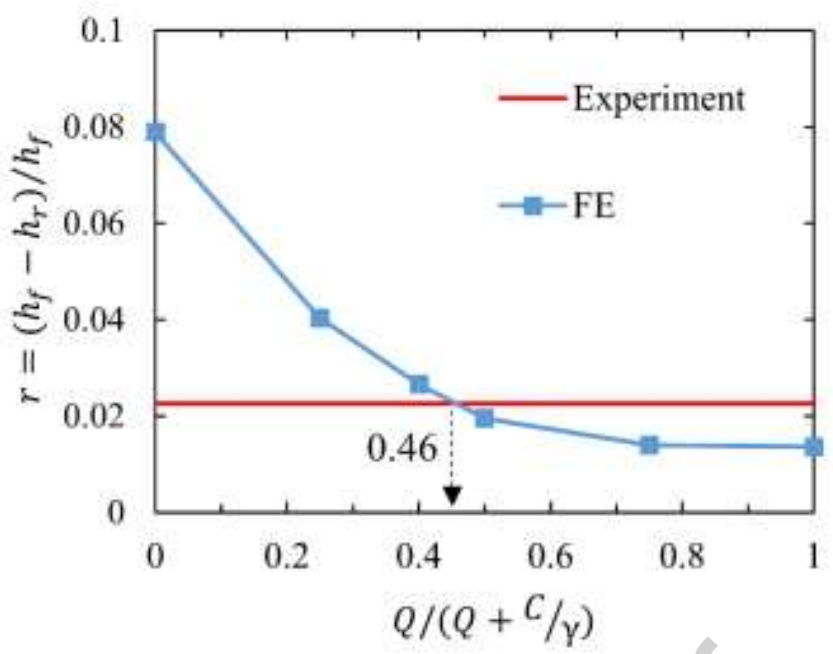

Fig. B.3. $r=\frac{h_{f}-h_{r}}{h_{f}}$ calculated for experimental and numerical hysteresis loops for AA2017. $r$ is represented as a function of $Q /(Q+C / \gamma)$ (ratio reflecting the contribution of isotropic hardening contribution in the overall harden ing law). The $Q /(Q+C / \gamma)$ value corresponding to the intersection point between numerical and experimental $r$ values determines the contribution of each hardening type in the overall hardening law for AA2017.
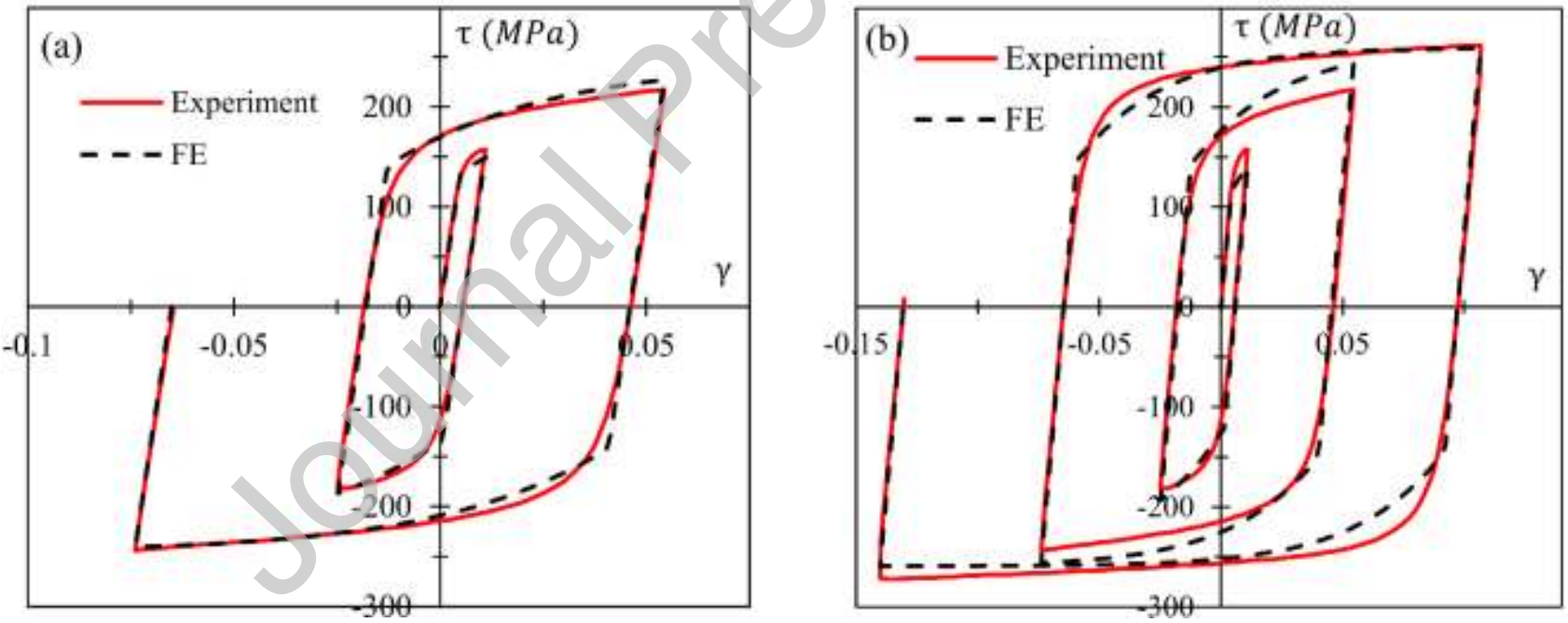

Fig. B.4. Experimental and identified numerical shear cyclic curves for AA2017 (a) 2 cycles; (b) 3 cycles. Experimental shear curves are obtained using the experimental apparatus presented in paragraph 3.1. Numerical shear cyclic curves are obtained using the inverse analys is technique. 5 parameters of the Chaboche laware identified taking into account the proposed hypothesis $b=\gamma$. 